\title{
How to foster innovation in SMEs: evidence of the effectiveness of a project-based technology transfer approach
}

\author{
Frederic Hilkenmeier $^{1}$ (D) . Christian Fechtelpeter ${ }^{2} \cdot$ Julian Decius $^{3,4}$
}

Accepted: 15 December 2021

(c) The Author(s) 2021

\begin{abstract}
One of the main challenges in technology transfer is to actively involve small and medium-sized enterprises (SMEs) — which are most in need of and benefit the most from collaborative Research and Development (R\&D) programs. This study presents a large-scale collaboration program which focuses on project-based technology transfer in SMEs with little to no prior experience in collaborative research projects. The core of this collaboration program is the temporary secondment of scientists from a Research and Technology Organization (RTO) into an SME to jointly work on a practical project objective- which is directly tailored to the demands of the SME. To evaluate the effectiveness of this approach in overcoming barriers related to finding the right collaboration partner, limited resources, and limited absorptive capabilities, we adopt the R\&D Lifecycle Model as a theoretical framework. Our findings, using self-reported and objective data from 106 different projects in a structural equation model, highlight that most SMEs in the considered cluster environment not only successfully mastered a challenging topic in the context of industry 4.0 that immediately benefits the organization, but also engaged in new R\&D projects to strengthen their scientific and technical human capital in the long term. Moreover, consistent with previous literature, we found that trust is the main driver within the R\&D Lifecycle Model both in building capabilities and economic growth. Based on these insights, we consider a long and close secondment of scientists to SMEs as key for collaboration projects and discuss implications for research and future technology transfer approaches.
\end{abstract}

Keywords Small and medium-sized enterprises (SME) - Technology transfer $\cdot$ R\&D lifecycle model $\cdot$ Drivers $\cdot$ Barriers $\cdot$ Transfer projects

\section{Introduction}

In times of ongoing digital transformation, industrial enterprises have to deal with everaccelerating change, shortening technology life cycles, and highly dynamic markets (e.g.,

Extended author information available on the last page of the article 
Green, 2007; Günsel, 2015; Rauter et al., 2018, van Lancker et al., 2016). At the same time, costs for research and development are rising, while complexity of products and services increases (Rauter et al., 2018; van Lancker et al., 2016). In this environment, a companies' competitive advantage no longer lies in its access to financial or physical capital, but in its knowledge-based resources and human capacity (Audretsch et al., 2014). This means, the ability to adapt to, implement, and drive technological changes determines a companies' competitiveness and capacity to grow (Günsel, 2015; Handoko et al., 2014).

However, the underlying basic research that enables such technological progress is often conducted in the public sector, i.e., by universities and government research laboratories (Feller et al., 2002; Sherwood \& Covin, 2008; Wirsich et al., 2016). The application of this basic research in products, services, or business processes can result in groundbreaking innovation on the companies' side (Baba et al., 2009; Spanos et al., 2015). To ensure that research results are disseminated and refined to be used in marketable products, processes, or new business models, governmental funding agencies try to strengthen the collaboration between Research and Technology Organizations (RTOs) and companies to achieve an efficient technology transfer (e.g., Bozeman, 2000; Hayter et al., 2020; Weckowska, 2015). Indeed, firms involved in such partnerships seem to be in a better position to adopt new technology and innovate faster, while also reducing the risks of misguided commercial decisions and thus improving their overall competitiveness (Audretsch et al., 2014; Grimpe \& Hussinger, 2013).

The focus of such government-facilitated technology transfer funding programs is often on small and medium-sized enterprises (SMEs; e.g., Jones \& Tilley, 2003). SMEs have a high economic and social importance and traditionally contribute substantially to the innovativeness and competitiveness of the whole economy (German Federal Ministry for Economic Affairs and Energy, 2020; Muller et al., 2017; Perkins, 2018). However, due to their limited resources and especially limited absorptive capabilities-i.e., limited internal capabilities for problem-solving and innovation-SMEs are especially challenged by the acceleration of research and development $(R \& D)$ processes, increasing R\&D costs, and the raising complexity of technical systems (Buganza et al., 2014; Decius \& Schaper, 2017; Günsel, 2015; Rauter et al., 2018; Spithoven et al., 2012; Strategic policy forum on digital entrepreneurship 2016; van Lancker et al., 2016). As a result, the share of innovative SMEs is dropping significantly (Zimmermann, 2018). However, because of their limited networks and thus difficulties in finding the right collaboration partner (Buganza et al., 2014), SMEs cooperate less closely and less often with academic partners than larger firms (e.g., Badillo et al., 2017). Though, once engaged, SMEs use their university-based connections to a greater extent than their larger counterparts (Link \& Rees, 1990; Ahn et al., 2018). In short: SMEs are most in need of and benefit the most from collaborative technology transfer programs.

It is advocated that technology transfer towards SMEs should follow the "scientific and technical human capital approach" (Bozeman, 2000). This entails that technology transfer-besides immediate positive effects from the project at hand (e.g., reaching defined goals) — should help build these absorptive capabilities. As pointed out by many scholars (e.g., Bishop et al., 2011; de Wit-de Vries et al., 2019; Fernandes et al., 2017; van Wijk et al., 2008), this capability of firms to assimilate and apply new knowledge is a necessary requirement for further technological advancements.

Even though governmental technology transfer programs put an emphasis on academic engagement in collaborative projects with SMEs (e.g., German Federal Ministry for Eco- 
nomic Affairs and Energy, 2020), research in this area is rather lacking (Buganza et al., 2014; de Wit-de Vries et al., 2019). To shed some light on this important but rather underexplored topic, the current study thus presents results of a large-scale collaboration program which focuses exclusively on project-based technology transfer between RTOs and SMEs.

This study employs the $R \& D$ Lifecycle Model of Perkmann et al. (2011; also see Albats et al., 2018; Fernandes et al., 2017) to evaluate to which extent the approach employed within this large-scale collaboration program could indeed help SMEs to find the right collaboration partner, circumvent their limited resources, and design transfer projects that are not only compatible with SMEs rather limited absorptive capabilities, but help extend these capabilities in the long run. The R\&D Lifecycle Model implies four sequential stages within a collaborative R\&D process: The first stage consists of organizational and individual "inputs", which affect the collaborative "in-process activities" (second stage) within the project. During the duration of the project, these "in-process activities" should lead to the generation of actual "outputs" (third stage). Finally, the exploitation of these outputs should result in a range of desirable "impacts" for all partners involved (fourth stage).

Addressing the call of Audretsch et al. (2014), the main contributions of this study are to present a successful dissemination approach, evaluate its effectiveness, examine the interplay of technology transfer factors within the SME context on a large empirical basis (as urged by de Wit-de Vries et al., 2019), and give implications for technology transfer programs focused on SMEs on the meso-level (Cunningham \& O'Reilly, 2018). Additionally, we address several research desiderata by (a) focusing on individual competences and resources (as suggested by Zaichenko, 2018), (b) adopting the perspective of the companies engaging in collaborations (as suggested by Cunningham \& O'Reilly, 2018; de Wit-de Vries et al., 2019), (c) considering not hardware aspects, but the knowledge facets of technology transfer (as suggested by Günsel, 2015), and (d) offering an empirical validation of the R\&D Lifecycle Model on the micro-level (as advised by Perkmann et al., 2011).

In the following, after briefly describing the large-scale collaboration program itself, we discuss transfer barriers, the selected approaches to overcome them (part 2), as well as evaluation criteria within the stages of the R\&D Lifecycle Model (part 3). After introducing our research design (part 4), we finally present the results of the empirical evaluation (part 5 ) and discuss them, including the study's limitations and implications for future technology transfer programs (part 6).

\section{A technology transfer program tailored to the needs of SMEs}

SMEs depend on external sources of knowledge to cope with the technology-induced change towards industry 4.0 (Rauch et al.,, 2018). To successfully collaborate with RTOs, acquire the knowledge needed, and remain prosperous on the market in the future (Handoko et al., 2014; Perkmann et al., 2011), SMEs need lowered or eliminated barriers to engage in technology transfer activities with RTOs (Bozeman, 2000; Feller et al., 2002; Hayter et al., 2020).

In the following, we will discuss these barriers and especially selected approaches to overcome them. However, to understand these approaches and the way they were selected in a better way, we will first briefly describe the large-scale collaboration program itself: it's $O W L$ - named after a geographical region in northwestern Germany - is a public-private 
partnership of more than 200 businesses of all sizes on the one hand, and 18 RTOs on the other hand. It can be considered the largest and most capable innovation cluster initiative in the context of Industry 4.0 in Germany (it's OWL, 2020; Götz \& Jankowska, 2017). It's $O W L$ combines two approaches: One side of the cluster-program consists of long-term and large-volume collaborative research projects between RTOs and larger firms with expertise in R\&D with a total project volume of around 100 million $€$ (it's OWL, 2020). These longterm and large-volume research projects can be classified as high-risk projects, i.e., the objectives are strongly future-oriented, which involves the building of a new knowledge base. The other side of the cluster-program is specifically aimed at SMEs whose internal capacities for R\&D are limited and which therefore cannot participate directly in those highrisk projects but should also benefit from the R\&D activities in the cluster. ${ }^{1}$ To disseminate the research results, it's $O W L$ tried to overcome existing transfer barriers in the following way:

Barriers related to finding the right collaboration partner. As shown by for instance Buganza et al. (2014), finding the right academic partner is especially difficult for SMEs as they have smaller, more localized networks. Moreover, they are often unable to identify RTOs that can answer their specific needs on their own (Masiello et al., 2015), but at the same time rarely come into contact with technology transfer intermediators like university technology transfer offices (Tödtling \& Kaufmann, 2001). Brokerage and bridge building are thus key practices of transfer and can promote the establishment of a collaboration (Lockett et al., 2008). To overcome these barriers, it's OWL's transfer activities take place within the described innovation cluster ecosystem, which-in accordance with the cluster concept of Porter (Porter, 1998; 2003; also see Curley \& Salmelin, 2018)—is characterized by a technological focus (in this case on intelligent technical systems and industry 4.0) and geographical proximity of the actors involved (in this case a region in northwestern Germany; Ketels, 2017; Ketels \& Memedovic, 2008). Geographical proximity facilitates exchange and assimilation of knowledge and thereby improves the likelihood of successful collaboration between academia and industry (Albats et al., 2018; Audretsch et al., 2014; Bishop et al., 2011; Herliana, 2015; Kind \& Meier zu Köcker, 2012; Petruzzeli \& Murgia, 2020; Schuh \& Woelk, 2017; Villani et al., 2017). Within this innovation cluster, the it's $O W L$ management agency employs an active bridging organization as an intermediator (Dumitrescu et al., 2016; Fechtelpeter et al., 2017; Fechtelpeter et al., 2018), which — unlike a classic technology transfer office - not only provide access to one RTO, but eighteen and,

\footnotetext{
${ }^{1}$ To give the reader a better understanding of the transfer initiative, below are brief descriptions of two transfer projects:As part of one transfer project, a supplier of adhesives for the furniture-, textile- and automotiveindustries optimized the production of reactive hot-melt adhesives in order to increase process reliability. The aim of the project partners was to develop a virtual sensor for online monitoring of adhesive viscosity during the production process. Because a direct measurement of the viscosity is not possible, the monitor combines a multitude of measurement data, which indirectly provide information about the reaction progress. Machine learning algorithms were used to detect a suitable mapping of measured variables to the viscosity.In another transfer project, the SME wanted to improve its production of complex foot-operated switches. These switches are used in the field of medical technology, for example in performing eye surgery. The sophisticated assembly is carried out by hand and demands maximum precision. As part of the transfer project, the partners developed an intelligent and intuitive assistance system, which explains work processes by means of a graphic user interface. A touchscreen is used to show the employee images and videos, which explain how the individual components are correctly assembled. In order to assure quality, process steps can be checked and documented in paperless form. The architecture of the assistance system is based on standardized process models and can be linked with other levels of the company IT.
} 
as suggested by Garengo (2019), actively develops and manages transfer activities like networking events between RTOs and SMEs.

Barriers related to limited resources. As discussed by Masiello et al. (2015) and others, SMEs often lack internal resources, and even if they do not, they are reluctant to invest time and money in collaborations with RTOs. This is presumably due to the risk of failure associated with such collaborations (see Proskuryakova et al.2017) as well as the "long term orientation of academics and the fundamental nature of [academic] research" (de Wit-de Vries et al., 2019, p. 1247; Albats et al., 2018). In addition, the length of time taken between initial collaboration proposal and actual start of the collaboration as well as the bureaucratic procedures to get there are seen as major obstacles (e.g., Bozeman, 2000). To protect the SME's limited resources, it's $O W L$ focuses on shorter transfer projects that only take about five to ten months (as suggested in Tavares, 2000, as cited in Buganza et al., 2014), can be applied unbureaucratically and easily, and usually starts shortly after the initial proposal is granted by the bridging organization - and not by a superordinate governmental funding agency (Dumitrescu et al., 2016; Fechtelpeter et al., 2017; Fechtelpeter et al., 2018). These transfer projects often build on know-how and project results that have been tested in industrial applications. Moreover, the RTO in any collaborative project is fully publicly funded (the cluster-internal bridging organization had a total public funding of about 6 million $€$ for these kinds of transfer projects); the company contributes additional efforts to the collaboration, e.g., in the form of personnel resources. Bringing own effort into the project increases the company's commitment to the project, which is considered a success factor for transfer collaborations (Barbolla \& Corredera, 2009). To prevent the risk of failure associated with the long-term orientation of many collaborative research endeavors and to increase the involvement and commitment of the companies, the transfer projects focus on specific tasks and challenges from business practice of the firm's discretion. This ensures that the intended results have a high relevance for the companies and that the companies have a high interest in assimilating the project results (Barbolla \& Corredera, 2009; Salmi \& Torkkeli, 2009). Both are key success factors for technology transfer and also help lifting the next set of barriers:

Barriers related to limited absorptive capabilities. As pointed out by many scholars (e.g., Bishop et al., 2011; de Wit-de Vries et al., 2019; Fernandes et al., 2017; van Wijk et al., 2008), the capability of firms to assimilate and apply new knowledge is a necessary requirement for successful technology transfer. Unfortunately, especially SMEs are often lacking in this regard (Buganza et al., 2014), presumably because larger firms "not only have more resources to devote to knowledge transfer [...], but may also have more diverse knowledge resources that enable absorption of new knowledge" (van Wijk et al., 2008, p. 844). In the conceptualization of its technology transfer instrument, it's $O W L$ puts great emphasis on overcoming this set of barriers: For one, as argued by van Wijk et al. (2008), industryacademia collaboration is often not focused on knowledge that is relevant for the firm at that particular point in time and might therefore not easily be exploited. As described in the last set of barriers, the transfer projects presented here are projects of the firm's discretion. The results of such a project should therefore be directly implementable in the firm's repertoire and knowledge base (Barbolla \& Corredera, 2009; Salmi \& Torkkeli, 2009; Santoro \& Chkrabarti, 2002; Motohashi, 2005). Following suggestions by Locke and Latham (1990), it's $O W L$ 's bridging organization monitors that the project goals are set to be challenging, but likely to fulfill (also see Garengo, 2019). In other words, the transfer projects enable 
SMEs to execute projects with a manageable element of technical risk that they would otherwise not be able to carry out due to a lack of scientific and technical human capacities or other resources. Furthermore, scholars have emphasized that especially informal learning processes - i.e., (tacit) knowledge exchange through feedback, reflection, and work experiences (Decius et al., 2019; Hilkenmeier et al., 2021) — are "a necessary condition to build up and maintain the formal technology transfer interaction" (Zaichenko, 2018, p. 370) and have "a major impact on the effectiveness of manufacturing technology transfer" (Bozeman 2000, p. 642). Therefore, as suggested by Demain (2001) and others, it's $O W L$ chooses an interpersonal transfer approach in which the academic partner is working in the facilities of the industrial partner. This secondment of scientists "is likely to be particularly effective in transferring tacit knowledge and skills from university to company" (Hicks, 1993, p. 372), and "the dual configuration of academic and practitioner entrepreneurial team configuration provides the basis for the most effective commercial performance" (Cunningham \& O'Reilly, 2018, p. 547). The positive effects of the secondment should be enhanced by the relatively long and close interaction between transferor and recipient (Amesse \& Cohendet, 2001; Salmi \& Torkkeli, 2009; Sherwood \& Covin, 2008).

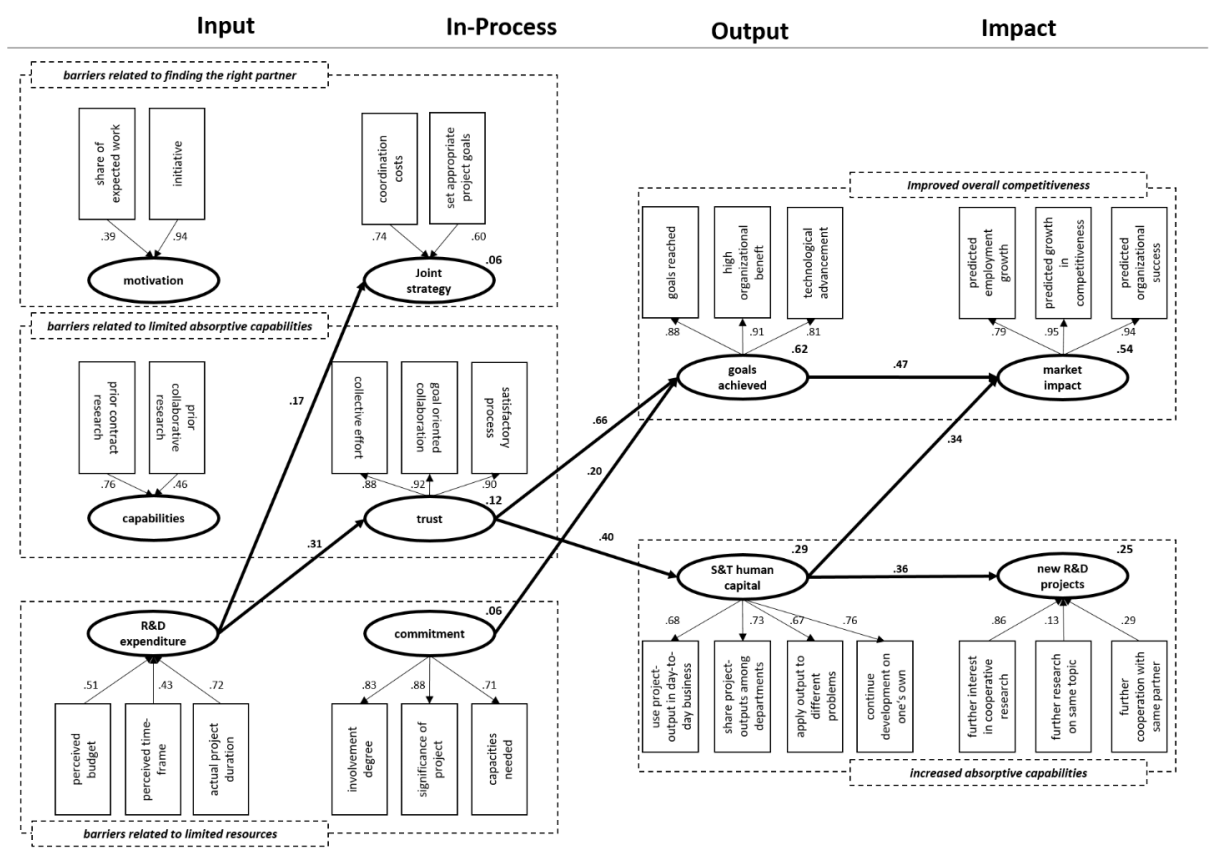

Fig. 1 Conceptual evaluation framework and empirical resultsNote. Rectangles represent manifest indicators, whereas ovals represent latent constructs. Arrows pointing from items to constructs indicate formatively operationalized constructs (with associated weights), whereas arrows pointing from constructs to items indicate reflexively operationalized constructs (with associated loadings). The model was specified in a way that all constructs from an earlier stage influence all constructs in the subsequent stage (e.g., motivation was assumed to influence joint strategy, trust, as well as commitment). However, for the sake of clarity, nonsignificant paths were omitted 


\section{Conceptual evaluation framework: the R\&D lifecycle model}

Above, we have identified three sets of barriers that hinder technology transfer into SMEs and presented the project-based transfer approach of the large-scale collaboration program it's $O W L$ 's to lift these barriers. To empirically test the effectiveness of this approach, we use the R\&D Lifecycle Model (Perkmann et al., 2011). More specifically, we use the R\&D Lifecycle Model and its extensions (Albats et al., 2018; Fernandes et al., 2017) as a theoretical framework to choose evaluation metrics (performance indicators) that best fit the transfer approach used and are relevant to the objectives of the it's OWL transfer approach (as intended by Albats et al., 2018; Rossi \& Rosli, 2015), namely increase a firm competitiveness as well as its absorptive capabilities. However, as stated by Perkmann et al., 2011, earlier stages of the R\&D lifecycle influence subsequent stages. Thus, we not only use performance indicators from the two later stages "outputs" and "impacts" to measure if the transfer projects lead to increased competitiveness and absorptive capabilities, but use indicators from all four stages to model the interplay between the different stages. By doing so, we utilize a structural equation model (SEM) further described in Sect. 4 and depicted in Fig. 1 to assess which impact is influenced by which output and to what extent. Likewise, we can determine which in-process activity influences which output and so on.

As discussed, the it's $O W L$ transfer approach tries to counteract barriers related to finding the right collaboration partner (e.g., Buganza et al., 2014; Lockett et al., 2008) by employing an active bridging organization as an intermediator which matches SMEs and RTOs within the cluster region. To evaluate this matching process at the "input" stage, we measure the transfer recipient's (the SME's) motivation during the initiation phase. While many scholars emphasize academia's motivation in engaging in transfer projects (e.g., Bercovitz \& Feldman, 2008; Perkmann et al., 2011), the industrial partner's motivation is equally important for a successful cooperation (see Fernandes et al., 2017). Relevant aspects to test whether the it's $O W L$ bridging organization's matching process generates motivated industrial partners are (a) whether the project was originally initiated by the SME (Bozeman, 2000), and (b) the share of expected work allocated to the industry partner during the preparation of the necessary project proposal (Albats et al., 2018; Cummings \& Teng, 2003). Most likely, this motivation during planning helps to develop a common perception of the R\&D challenge to be solved in the transfer project at hand, which leads to a joint strategy during the "in-process activities". As Cummings and Teng (2003), Morandi (2013) or Schultz et al. (2020) have shown, a joint strategy, i.e., a common perception of the aspired goals and the way to reach them substantially increases a project's performance. Joint strategy consists of common procedures and goals, indicating the level of ambition of both partners (Mora-Valentin et al., 2004). As shown by Morandi (2013), this is especially important when the project partners' activities are mutually interdependent, as is the case in the technology transfer approach with long and close secondment of scientists to the company presented here. A further aspect of joint strategy and indicating whether it's OWL's bridging agency helps finding the right collaboration partner is the effort of both partners put in the collaboration, whereby both partners should be equally involved (Perkmann et al., 2011). Finally, defining the joint strategy should reveal possible coordination efforts that "minimize the confusion, conflicts of interests or mismatch in the vision of the project implementation" (Albats et al., 2018, p. 397) that arise due to differences in culture, priori- 
ties, and values between RTOs and SMEs (Banal-Estanol et al., 2013; Cummings \& Teng, 2003; de Wit-de Vries et al., 2019; Morandi, 2013).

To circumvent barriers related to limited resources, it's $O W L$ focuses on shorter, unbureaucratic transfer projects and with a fully publicly funded RTO transfer partner. To track the influence of the firm's resources on its engagement in the it's $O W L$ transfer project, we measure the SME's expenditure at the "input" stage. As for instance stated by Perkmann et al. (2011), expenditure is a major factor in any type of R\&D activity and has a positive impact on innovation potential (Nepelski et al., 2019; Ahn et al., 2018). While expenditure measures the resources dedicated at the "input" stage at the start of the project, the "inprocess activity" commitment reflects the transfer recipients' organizational commitment to prioritize the transfer project, i.e. whether the SME has enough resources to commit to the project over its day-to-day business (Barbolla \& Corredera, 2009; Barnes et al., 2002; Cummings \& Teng, 2003; Plewa \& Quester, 2006). Moreover, commitment is indicated by the staff's involvement degree, i.e. managerial and non-managerial support and assistance from the SME's staff who are not directly involved in the transfer project, which is positively associated with transfer performance (see Liu \& Hsiao, 2019). Furthermore, commitment is indicated by the perceived importance of the project within the organization, e.g., whether senior management sees it as a priority. Otherwise, it might again be hard to commit the resources needed (e.g., Barnes et al., 2002; Cummings \& Teng, 2003; Mora-Valentin et al., 2004).

Finally, to counteract barriers related to limited absorptive capabilities, it's OWL employs transfer projects with manageable risk and of the firm's discretion that (ideally) lead to results that can be implemented in the firm's products, services or processes shortly after the end of the project. Moreover, it's $O W L$ chooses an interpersonal transfer approach in which the seconded academic partner (also known as "boundary spanner"; de Wit-de Vries et al., 2019) is working in the facilities of the industrial partner, which should be the most effective basis for technology transfer (Cunningham \& O'Reilly, 2018; Hicks, 1993). To test whether this approach actually negates the need for pre-existing absorptive capabilities at the "input" stage, we examine the influence of prior experience by evaluating the extent of previous collaborative research or contract research, which usually increases performance during the cooperation and contributes to the reduction of transfer barriers (e.g., Bellini et al., 2019, Barbolla \& Corredera, 2009; Santoro \& Bierly, 2006; van Wijk et al., 2008). The collaborative working style und thus close communication between industrial and academic partner should facilitate building trust at the "in-process" stage (e.g., Kauppila et al., 2015; Salmi \& Torkkeli, 2009; Sherwood \& Covin, 2008), especially for more unexperienced industrial partners, who fear that their academic counterparts might not be working on the same goals, or have a hidden agenda (De Wit-de Vries et al., 2019). Thus, trust is indicated by a more goal-oriented work (Mora-Valentin et al., 2004) and a higher satisfaction with the collaboration process (De Wit-de Vries et al., 2019). Indeed, trust seems to be a key requirement for transfer projects to successfully reach their desired outcomes, to which we turn next (e.g., Barbolla \& Corredera, 2009; Bellini et al., 2019; Kauppila et al., 2015; Lockett et al., 2008; Oliver et al., 2020; Santoro \& Bierly, 2006).

As discussed in the introduction of this manuscript, firms who are involved in academiaindustry-collaborations and overcame the aforementioned transfer barriers should be able to implement new technologies into innovative products, process, services, or business models in a faster and less risky way, thus improving their overall innovation capabilities 
and competitiveness - both immediately and in the long run (e.g., Audretsch et al., 2014; Bishop et al., 2011; Grimpe \& Hussinger, 2013). Besides these direct positive effects from the collaborative project at hand, these firms should also build absorptive capabilities during the collaboration: Increased absorptive capabilities should not only help to further disseminate the project's results within the organization, but also enable the company for further technological advancements in new research topics (e.g., Bozeman, 2000; van Wijk et al., 2008). To match these multi-faceted outcomes of project-based technology-transfer within the R\&D Lifecycle Model, we investigate both performance (i.e., competitiveness) and innovativeness (i.e., absorptive capabilities) immediately and (at least prospectively) in the long run.

The immediate "outputs" thus cover more tangible and direct benefits, i.e. whether the transfer project achieves its defined goals (Grimaldi \& von Tunzelmann, 2002; Lockett et al., 2008) and therefore increases the SME's overall competitiveness short-term; and more intangible effects of the collaboration, namely building scientific and technical (S\&T) human capital at the project level (Bozeman et al., 2001), which, according to Bozeman et al. (2015), is at least as valuable as the beneficial direct outputs and helps increase the firm's absorptive capabilities. Increased $S \&$ T human capital at the project level shows that transfer recipients have mastered the transferred technologies and are able to use them in day-to-day business as well as apply them throughout the company and to new problems and projects (also see Argote et al., 2000 for intra-organizational knowledge transfer).

In the more future-oriented "impact" stage, long-lasting growth in competitiveness is determined by the market impact, i.e., the commercial success of the transferred technology that should manifest itself in overall organizational growth and success (Bozeman et al., 2015; Perkmann et al., 2011). Sustainable innovativeness through increased absorptive capabilities on the other hand is evidenced by engagement in new R\&D projects in the future. Therefore, the existence of new early-stage research projects is a suitable measure (Perkmann et al., 2011).

\section{Methods}

\subsection{General research design}

As outlined in the introduction, our objectives are to (a) evaluate the effectiveness of the it's $O W L$ transfer approach designed for the demands of SMEs and to (b) determine the main drivers that contribute to successful transfer projects within this context. To evaluate the approach's effectiveness, we report and discuss descriptive statistics of the R\&D Lifecycle Model's later stages "output" and "impact" explicated in part 3. If the transfer approach has been successful, the transfer recipients should report tangible and intangible outputs and impacts like high organizational benefits, technological advancements (i.e., achieved innovation leaps), or engagement in new R\&D projects. As detailed below, we therefore employ both objective and subjective data as well as retrospective and prospective measures to obtain a holistic evaluation framework (as recommended by e.g., Lockett et al., 2008; Perkmann et al., 2011).

To determine the main drivers that contribute to successful transfer projects, we employ a partial least squares structural equation model (PLS-SEM; cf. e.g., Goller \& Hilkenmeier 
forthcoming; Hair, Hult et al., 2014) using the R package plspm v0.4.7 (Sanchez et al., 2015). The PLS-SEM approach offers several features that make it particularly suitable for the study at hand and quantitative technology transfer studies as a whole (see Ibanez et al., 2021; Leischnig \& Geigenmüller, 2020; or Stolze \& Sailer, 2021, for recent examples in The Journal of Technology Transfer): First, since it is based on a series of ordinary least squares (OLS) regression, it can handle even complex causal predictive models with relatively small sample sizes. Second, PLS-SEM allows incorporation of formative constructs (i.e., grouping variables), which cover different aspects of a construct (Chin, 2010). Therefore, the PLS-SEM approach fully meets the demands of our study: The underlying R\&D lifecycle framework is rather complex and uses a number of abstract and inclusive "high bandwidth" constructs (Ones \& Viswesvaran, 1996), which are best modelled as formative constructs. Furthermore, the sample size (and even the underlying population) of it's $O W L$ transfer projects is relatively small, requiring an approach with high statistical power. These benefits come along with at least one relevant downside: PLS-SEM does not offer global goodnessof-fit criteria like $\chi^{2}$ significance test, $C F I$, or RMSEA to assess how well a specified model fits the observed data. Instead, as in regression analyses, the interpretation of the results focuses on path coefficients and $\mathrm{R}^{2}$ values (Goller \& Hilkenmeier forthcoming). However, since the aim of the present research endeavor is on identifying those aspects of the R\&D Lifecycle Model that most strongly predict transfer success, this downside is negligible (Goller \& Hilkenmeier forthcoming).

\subsection{Procedure and sample}

In the time span between 2014 and 2017, it's $O W L$ conducted 171 transfer projects with a total public funding of about 6 million $€$. Approximately three months after each project, an online questionnaire was sent to the transfer recipient (i.e., the principal collaborator within the SME serving as contact person). As shown by Bandura (1977), Ajzen (1991), or-more specific in the transfer context-Mora-Valentin et al. (2004), it is the subjective perception that drives behavior. Therefore, asking for the transfer recipients' perception of inputs, inprocess-activities, and outputs should lead to a high predictive validity in regard to the lasting impact of the transfer project. As suggested by e.g., Lockett et al. (2008) and described above, our evaluation also includes prospective indicators of anticipated long-term impacts.

By contacting the transfer recipient directly, we ensure that the evaluator is the same person who worked on the project. This questionnaire was not anonymized, but it was made clear that the individual answers would remain confidential within the research institution (represented by the first author who is not a part of the cluster). The results were reported only in aggregate form to the management of the leading-edge cluster or the government funding agency. De-anonymizing the questionnaire allowed us to enrich the survey data with more objective measures when useful (see below). These data were taken from a project proposal (approx. ten pages) that the project consortium (SME and RTO) had to write during the planning and application phase of a transfer project. Overall, we gathered data from 106 different transfer projects, representing a return rate of $62 \%$. However, because 16 of these 106 evaluated projects had up to three principal collaborators within the SME, we get data from 125 participants (for these cases, the average within-group-agreement between collaborators from the same firm was 0.81 , which, according to LeBreton $\&$ Senter, 2008, can be classified as strong agreement). 


\subsection{Measures and operationalization}

The online questionnaire sent to the transfer recipient contained 25 survey items, each to answer either on a three-point or a six-point Likert-scale ranging from "strongly disagree" to "strongly agree". In addition, we extracted 4 information from each project proposal and merged these rather objective data with the survey data. Due to cross-loadings (see results section below) we had to exclude one survey item. A brief overview of the remaining 28

Table 1 Indicators Used in the Evaluation Including Descriptive Statistics

\begin{tabular}{|c|c|c|c|c|c|c|c|c|}
\hline \multirow{2}{*}{$\begin{array}{l}\text { Process stage } \\
\text { Input }\end{array}$} & \multirow{2}{*}{$\begin{array}{l}\text { Factor } \\
\text { R\&D }\end{array}$} & \multirow{2}{*}{$\begin{array}{l}\text { Item } \\
\text { Appropriate budget }^{2}\end{array}$} & \multicolumn{6}{|c|}{$\begin{array}{l}\text { Results in } \% \\
\text { strongly disagree }<->\text { strongly agree }\end{array}$} \\
\hline & & & 0.0 & & 19.2 & & & 80.8 \\
\hline & Expenditure & Appropriate timeframe ${ }^{2}$ & 3.2 & & 33.6 & & & 63.2 \\
\hline & & Total project duration in month ${ }^{3,5}$ & & & 8.1 & & & \\
\hline & Capabilities & Prior collaborative research ${ }^{1,5}$ & 29.0 & & & & & 71.0 \\
\hline & & $\begin{array}{l}\text { Prior commissioning of contract } \\
\text { research }^{1,5}\end{array}$ & 45.0 & & & & & 55.0 \\
\hline & Motivation & Initiative & 0.0 & 4.8 & 14.4 & 49.6 & 20.0 & 11.2 \\
\hline & & Share of expected work ${ }^{4,5}$ & & & 49.0 & & & \\
\hline \multirow[t]{8}{*}{ In-Process } & Joint strategy & Efforts for common understanding ${ }^{2}$ & 2.4 & & 18.4 & & & 79.2 \\
\hline & & Appropriate goals ${ }^{2}$ & 0.0 & & 23.2 & & & 76.8 \\
\hline & Trust & Goal-oriented collaboration & 0.8 & 3.2 & 4.8 & 8.0 & 26.4 & 56.8 \\
\hline & & Satisfactory collaboration & 1.6 & 2.4 & 7.2 & 15.2 & 40.8 & 32.8 \\
\hline & & Experience to work together & 0.8 & 3.2 & 4.8 & 8.0 & 26.4 & 56.8 \\
\hline & Commitment & Project priority & 0.0 & 6.4 & 7.2 & 32.0 & 33.6 & 20.8 \\
\hline & & Organizational support & 1.6 & 1.6 & 7.2 & 24.0 & 36.0 & 29.6 \\
\hline & & Focus on Project & 1.6 & 5.6 & 12.0 & 22.4 & 33.6 & 24.8 \\
\hline \multirow[t]{7}{*}{ Output } & Goals & Goals reached & 0.8 & 4.0 & 7.2 & 20.0 & 40.0 & 28.0 \\
\hline & achieved & High organizational benefit & 0.8 & 4.8 & 8.8 & 20.0 & 34.4 & 31.2 \\
\hline & & Technological advancement & 1.6 & 4.8 & 8.0 & 18.4 & 42.4 & 24.8 \\
\hline & $\begin{array}{l}\text { S\&T human } \\
\text { capital }\end{array}$ & $\begin{array}{l}\text { Use project output in day-to-day } \\
\text { business }\end{array}$ & 5.6 & 13.6 & 12.0 & 28 & 20.8 & 20.0 \\
\hline & & $\begin{array}{l}\text { Share project outputs among } \\
\text { departments }\end{array}$ & 0.0 & 12.0 & 5.6 & 28.0 & 35.2 & 19.2 \\
\hline & & Apply output to different problems & 2.4 & 11.2 & 11.2 & 13.6 & 37.6 & 24.0 \\
\hline & & Continue research on one's own & 0.8 & 6.4 & 4.8 & 21.6 & 28.8 & 37.6 \\
\hline \multirow[t]{6}{*}{ Impact } & Market & Predicted employment growth & 8.0 & 12.8 & 20.8 & 21.6 & 22.4 & 14.4 \\
\hline & impact & $\begin{array}{l}\text { Predicted growth in } \\
\text { competitiveness }\end{array}$ & 1.6 & 2.4 & 4.0 & 24.8 & 31.2 & 36.0 \\
\hline & & Predicted organizational success & 1.6 & 0.8 & 8.0 & 20.8 & 34.4 & 34.4 \\
\hline & $\begin{array}{l}\text { New R\&D } \\
\text { projects }\end{array}$ & $\begin{array}{l}\text { Further interest in cooperative } \\
\text { research }\end{array}$ & 0.0 & 0.8 & 4.8 & 10.4 & 21.6 & 62.4 \\
\hline & & Further research on same topic ${ }^{1}$ & 43.2 & & & & & 56.8 \\
\hline & & $\begin{array}{l}\text { Further cooperation with same } \\
\text { partner }^{1}\end{array}$ & 39.6 & & & & & 60.4 \\
\hline
\end{tabular}

Note. ${ }^{1}$ Indicators are true or false $;{ }^{2}$ Indicators are on a three-point scale $;{ }^{3}$ Duration in month $;{ }^{4}$ In percent;

${ }^{5}$ Information extracted from the project proposal; all other indicators were answered by transfer recipients on a six-point Likert scale. A full description of all indicators, their measurement, means, standard deviations, and a short reference to locate the indicator in the technology transfer literature are provided as Electronic Supplementary Information 
indicators including their descriptive statistics can be found in Table 1. A full description of all indicators, their measurement, means, standard deviations, and a short reference to locate the indicator in the technology transfer literature are provided as Electronic Supplementary Information.

\section{Results}

\subsection{Effectiveness of the it's OWL focused transfer projects}

Besides achieving the specific sub-goals of each project (which were defined in the project proposal, e.g., development of a new function for a product based on machine learning methods, see again ${ }^{1}$ ), the overarching goal of all it's $O W L$ transfer projects was to strengthen the SMEs' scientific and technical human capital and thereby increasing their innovative and absorptive capabilities. The descriptive statistics for all indicators used in the R\&D Lifecycle Model can be found in Table 1. As we will discuss in more detail below, the descriptive results indeed suggest that most projects achieved both the specific sub-goals and the overarching increase in absorptive capabilities: More than $65 \%$ of the transfer recipients "agree" or "strongly agree" that the objectives of the transfer project were achieved and that the resulting technological advancement had an immediate organizational benefit (see descriptive statistics of goals achieved in Table 1). Likewise, at the time of the evaluation, about $60 \%$ of the SMEs were already working on a follow-up project (see descriptive statistics of New $R \& D$ projects in Table 1).

\subsection{Drivers of successful technology tansfer projects: assessment of the measurement model}

In order to identify the main drivers of successful technology transfer projects between SMEs and RTOs within the it's OWL transfer approach, we consider the R\&D Lifecycle Model as a theoretical framework for the assumed relationships (see Fig. 1), and therefore apply structural equation modeling (SEM) using the partial least squares (PLS) approach. As described in Goller and Hilkenmeier (forthcoming), or Hair et al. (2014), analysis using PLS-SEM is usually conducted in two separate stages: (a) assessment of the measurement model and (b) assessment of the structural model. Whereas analyses at the first stage ensure that the data are indeed suitable for the theoretical model at hand, analyses at the second stage deal with the interplay of the different factors within the model.

A first step to ensure the appropriateness between empirical data and theoretical model is to examine whether the empirical sample size is sufficient to find any substantial effects (statistical power). As suggested by Hair, Hult et al. (2014), the power analysis focuses on the part of the model with the highest number of predictors. As can be seen in Fig. 1, the highest number of predictors of any construct is three. Using R's pwr package v1.2-2 (Champely, 2018), we determined a minimum sample size of 100 to achieve a statistical power of $80 \%$ for detecting low-to-medium effect sizes $\left(R^{2}\right.$ values of at least 0.10$)$ on a significance level of $5 \%$. With a sample size of $N=125$ in the present study, this requirement is therefore fulfilled. 
Second, as most of our indicators were answered using a self-report questionnaire, our data might suffer from common method variance, even though - as a procedural remedy suggested by Podsakoff et al. (2003) — we used different response formats throughout the questionnaire (see methods section above). Applying Harman's (1960) test, the single factor for all 28 items (self-reports and objective data from the project-proposal) accounts for $26.5 \%$ of the overall variance, whereas the single factor for all 24 self-reported survey items (see supplementary information) accounts for $30.8 \%$ of the overall variance, both of which is well below the critical threshold of 50\%. Thus, according to Harman's test, there is no indication of a high common method variance in our data.

Whereas the first and second step dealt with the suitability of the data in general, the third step is concerned with the relationship between the factors (constructs) and their respective indicators. For reflectively operationalized constructs (see Fig. 1 as well as Electronic Supplementary Information), it is necessary to ensure a high proportion of common variance between the manifest items (i.e., to ensure that all items measure the same construct reliably). Reliability was assessed by calculating the factor loadings as well as Cronbach's alpha for each reflective construct. With factor loadings and Cronbach's alpha $>0.70$, all reflectively operationalized constructs can be considered reliable (Hair, Black et al., 2014). Only the construct $S \& T$ human capital slightly misses these criteria. However, with all factor loadings $\geq 0.67$ and Cronbach's alpha $=0.68$, this construct can still be seen as reliable enough (see Table 2 column "Cronbach's alpha" and Fig. 1 for factor loadings).

For formatively operationalized constructs, indicators do not need to correlate but must cover different aspects of a construct to form a common factor. Therefore, collinearity between the indicators needs to be checked to ensure stability of the estimated coefficients. This means, formatively operationalized constructs cannot be evaluated in the same way as reflectively operationalized constructs (Sanchez et al., 2015). Thus, instead of reporting Cronbach's alpha as a measure of reliability, we report variance inflation factors (VIF)

Table 2 Reliability and Collinearity of all Constructs

\begin{tabular}{llllll}
\hline Process stage & Factor & $\begin{array}{l}\text { Cronbach's alpha } \\
\text { (reflexive constructs) }\end{array}$ & $\begin{array}{l}\text { AVE } \\
\text { (reflexive } \\
\text { constructs) }\end{array}$ & $\begin{array}{l}\text { Max. VIF } \\
\text { (formative } \\
\text { constructs) }\end{array}$ & $\begin{array}{l}\text { Max. } \\
\text { VIF } \\
\text { (process } \\
\text { stage) }\end{array}$ \\
\hline Input & R\&D expenditure & & & 1.01 & 1.01 \\
& Motivation & & & 1.00 & 1.10 \\
In-Process & Capabilities & Joint strategy & & & 1.02 \\
& Trust & 0.88 & 0.81 & & 1.68 \\
& Commitment & 0.76 & 0.65 & & 1.72 \\
Output & Goals achieved & 0.83 & 0.75 & & 1.32 \\
& S\&T human capital & 0.68 & 0.51 & & \\
\hline
\end{tabular}

Note. To assess reliability for reflexively operationalized constructs, we calculated Cronbach's alpha and the average variance extracted (AVE). To assess collinearity between items of a formatively operationalized construct, we calculated the variance inflation factors (VIF). The largest VIF for each formatively operationalized construct is shown here (max. VIF). Likewise, to assess collinearity between different predictors / constructs, we calculated the VIF for each construct on a given process stage. The largest VIF for each process stage is shown here (max. VIF) 
as a measure of collinearity for formatively operationalized constructs (Hair, Black et al., 2014; Kline, 2016). All resulting VIFs were smaller than two and therefore indicate that collinearity is unproblematic in the current dataset (see Table 2 column "Max. VIF formative constructs"; see O'Brien, 2007, for an in-depth view into collinearity).

In step 3, we focused on each construct and its indicators separately; in step 4 we turn to convergent validity and discriminant validity between the constructs. On the item-level, we checked each indicator's loading on the target construct against its cross-loadings on all other constructs. As described in the methods section above, one of the original 29 indicators had higher cross-loadings on several other constructs than on its target construct. That indicator was therefore excluded and the whole analyses were rerun (all analyses presented here refer to the final 28 indicators). As can be seen in the Electronic Supplementary Information, all of these 28 items loaded the highest on their respective constructs, confirming the indicators' discriminant validity. On the construct-level, we checked the average variance extracted (AVE) and employed the Fornell-Larcker-criterion for reflectively operationalized constructs (Fornell \& Larcker, 1981). AVE is the average amount of variation that a latent construct explains in its indicators (Farrell, 2010). Thus, analogous to a high Cronbach's alpha value, an AVE $>0.50$ indicates that items of a given factor are indeed a reliable measure of that construct (Hilkenmeier et al., 2020). As can be seen in Table 2 (column "AVE"), all reflectively operationalized constructs exceed this threshold and therefore display good convergent validity. To test discriminant validity on the construct level, we compared the AVE (representing the average amount of variance that a construct explains in its indicators) against the squared intercorrelations between the constructs in the model (representing the amount of variance a construct shares with each other construct). Discriminant validity is established when a construct is more closely related to its own indicators than to any other construct within the contextual framework. As can be seen in Table 3, the square root of each reflectively operationalized construct's AVE (shown in the diagonal) is always higher than the highest correlation with any other construct, indicating discriminant validity (Fornell \& Larcker, 1981; Hilkenmeier et al., 2020; please note that the alternative approach to estab-

Table 3 Intercorrelations Between the Factors

\begin{tabular}{|c|c|c|c|c|c|c|c|c|c|c|c|}
\hline Factor & $\begin{array}{l}\text { Num- } \\
\text { ber of } \\
\text { items }\end{array}$ & 1 & 2 & 3 & 4 & 5 & 6 & 7 & 8 & 9 & 10 \\
\hline 1. Capabilities & 2 & - & & & & & & & & & \\
\hline 2. R\&D expenditure & 3 & 0.02 & - & & & & & & & & \\
\hline 3. Motivation & 2 & 0.02 & 0.07 & - & & & & & & & \\
\hline 4. Commitment & 3 & -0.21 & 0.13 & -0.02 & 0.81 & & & & & & \\
\hline 5. Joint strategy & 2 & 0.04 & 0.18 & 0.18 & 0.35 & - & & & & & \\
\hline 6. Trust & 3 & -0.08 & 0.31 & 0.12 & 0.51 & 0.54 & 0.90 & & & & \\
\hline 7. Goals achieved & 3 & -0.13 & 0.25 & 0.16 & 0.54 & 0.44 & 0.77 & 0.87 & & & \\
\hline 8. S\&T human capital & 4 & -0.07 & 0.12 & 0.14 & 0.37 & 0.37 & 0.52 & 0.65 & 0.71 & & \\
\hline 9. Market impact & 3 & -0.02 & 0.11 & 0.11 & 0.37 & 0.22 & 0.48 & 0.69 & 0.65 & 0.90 & \\
\hline 10. New R\&D projects & 3 & 0.04 & 0.08 & 0.01 & 0.41 & 0.30 & 0.48 & 0.42 & 0.48 & 0.49 & - \\
\hline
\end{tabular}

Note. All $r \geq .18$ differ significantly from zero with $p<.05$ (two-tailed test). For reflexively operationalized constructs, the square-root of the AVE is shown in the diagonals in italics. For discriminant validity between the constructs, the square-root of the AVE of the construct in question must be higher than the highest correlation of that construct with any other construct in the model 
lish discriminant validity via HTMT, although not reported here, also indicates discriminant validity, see Henseler et al., 2015). It follows that, based on the presented analyses, both the reflectively operationalized constructs as well as the formatively operationalized constructs can be used to estimate the assumed relationships in the structural model.

\subsection{Drivers of successful technology transfer projects: assessment of the structural model}

Since the evaluation of the measurement model has shown satisfactory results, the second stage of the data analysis focuses on the structural model. As described in the general research design above, PLS-SEM uses a set of OLS-based regressions to obtain parameter estimates in this model part. Therefore, as a first step, it is important to again check for collinearity, this time among all constructs of a given process stage of the R\&D Lifecycle Model. As can be seen in Table 2 (column "Max. VIF process stage"), the resulting VIFs are again all below 2, which indicate that the path coefficients estimated by the PLS-SEM algorithm are not affected by collinearity. Therefore, $R^{2}$ values of the endogenous constructs and path coefficients are inspected next.

Figure 1 shows the estimated loadings ( $\lambda$; for reflectively operationalized constructs), outer weights ( $w$; for formatively operationalized constructs), standardized path coefficients $(\beta)$, and explained variance $\left(R^{2}\right)$ for each endogenous variable. As described in the introduction and in the discussion of the conceptual evaluation framework, the R\&D Lifecycle Model implies causal relationships between the four stages, meaning that each construct on an earlier stage should influence all constructs in the subsequent stage. Accordingly, we estimated the PLS-Model in that way. However, for the sake of clarity, nonsignificant paths were omitted from Fig. 1.

As Fig. 1 shows, the "impact" factor new $R \& D$ projects has an $R^{2}$ value of 0.25 whereas market impact has an $R^{2}$ value of 0.54 , which, in Cohen's terms (1988), can both be classified as strong effects. This means that $25 \%$ of the variance in new R\&D projects can be explained by its predictors, namely the two "output" factors goals achieved and $S \& T$ human capital. In other words, without knowing anything about the involved SME in detail (e.g., R\&D challenges, size, sector, products), we can explain $25 \%$ of the SME's future R\&D efforts simply by knowing to what extent the SME has achieved the goals of the transfer project and to what extent it has increased its $S \& T$ human capital. Interestingly, goals achieved is the strongest driver for market impact $(\beta=0.47)$, whereas $S \& T$ human capital is the strongest driver for new $R \& D$ projects $(\beta=0.36)$. In fact, $S \& T$ human capital is the only significant driver for new $R \& D$ projects, suggesting possible differential effects for increasing competitiveness and increasing absorptive capabilities in the long run.

Turning to the previous stage of the R\&D Lifecycle Model, Fig. 1 shows that the "output" factors goals achieved and $S \& T$ human capital have $R^{2}$ values of 0.62 and 0.29 , respectively, which can again be classified as strong effects. The most important driver for both "outputs" is trust ( $\beta=0.66$ and $\beta=0.40$, respectively). In fact, within the transfer approach presented here, joint strategy influenced neither of these factors, and commitment only showed a moderate effect on goals achieved.

Again turning to the previous stage of the R\&D Lifecycle Model, Fig. 1 shows that none of the "in-process activities" can be explained particularly well, with $R^{2}$ values ranging between 0.06 and 0.12 (all small effects; Cohen, 1988). Indeed, the only significant path 
coefficients between "input" stage and "in process" stage lead from $R \& D$ expenditure to joint strategy $(\beta=0.17)$ and trust $(\beta=0.31)$.

After investigating the interplay between the different factors at the different stages of the R\&D Lifecycle model, we transform the results of the PLS study into importance-performance maps for our two constructs of the "output" stage as well as for the two constructs from the "impact" stage (e.g., Hair et al., 2014). An importance-performance map identifies predictors with a relatively high importance and relatively low performance. Managerial efforts should in general concentrate on these predictors (lower right quadrant in each importance-performance map of Fig. 2), as they should be relatively susceptible to change (due to their current low performance) and yet offer strong improvements on the target construct (due to their relative importance). As a measure of performance, we used the construct mean scores (see Electronic Supplementary Information), each rescaled as a percentage value ranging from 0 to 100 . As a measure of importance, we used the total effects of each factor on the respective target construct as estimated by the PLS algorithm.

As can be seen in the upper part of Fig. 2, the importance-performance maps for goals achieved and $S \& T$ human capital suggest concentrating on commitment, and-to a lower degree - on trust and $R \& D$ expenditure, even though the performance of the latter two is already quite high. As depicted in the lower part of Fig. 2, importance-performance maps for market impact and new R\&D projects suggest concentrating on S\&T human capital.
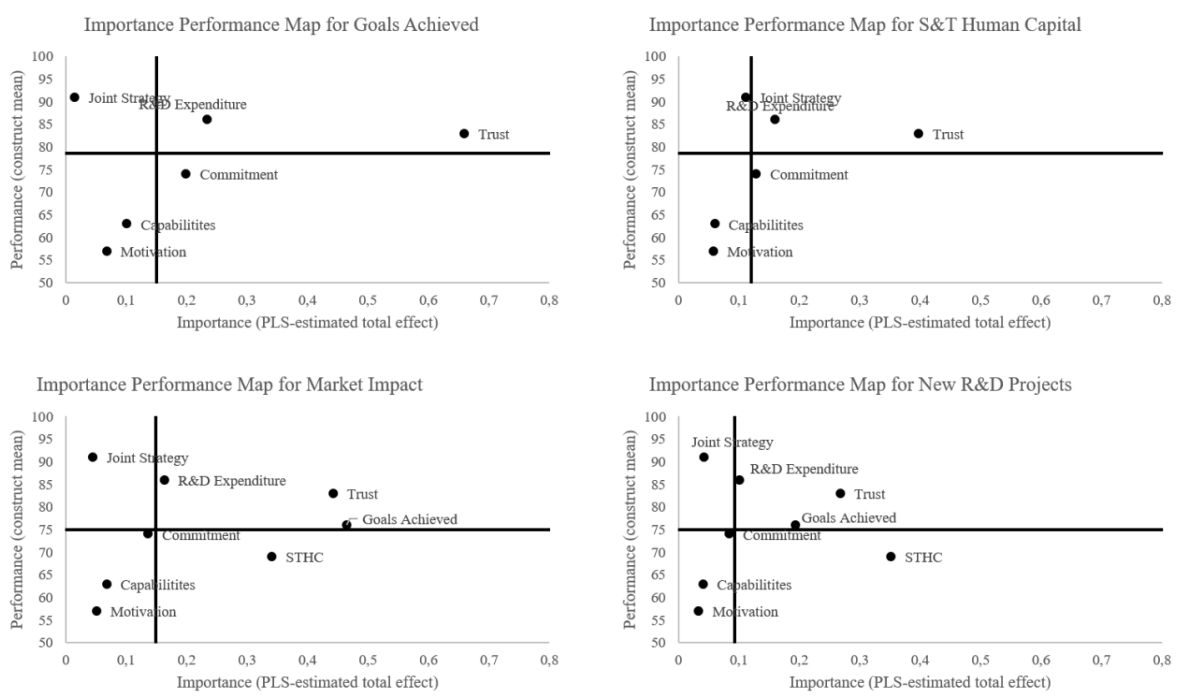

Fig. 2 Importance-performance maps for the two "outputs" and the two "impacts". Quadrants are formed by median-split on both performance (construct mean scores rescaled as a percentage value) and importance (PLS-estimated total effects). 


\section{Discussion}

In the following, we first summarize the main findings of our study and place them in the context of previous research. In doing this, we follow the stages of the R\&D Lifecycle Model (Perkmann et al., 2011) which has served as conceptual framework within our study. Finally, we discuss implications for technology transfer approaches based on the it's $O W L$ approach we considered in our study (i.e. consideration of technology transfer activities in clusters as well as project-based transfer collaborations). We focus on the essential feature of long and intensive secondments of scientists to SMEs and the associated duration of transfer projects.

\subsection{Summary of the findings}

The aim of technology transfer activities is to provide companies and their employees with advanced technologies and methods as well as scientific research results. The companies convert the transfer results and developments into innovative products, processes, or business models, and are empowered to advance technology as well as product and process development on their own (Bozeman, 2000; Diebold et al., 2015; Link, et al., 2007).

Overall, the it's $O W L$ transfer projects have achieved this objective. As can be seen in the descriptive statistics (Table 1 as well as Electronic Supplementary Information), about two thirds of the projects led to an immediate technological advancement within the transfer recipient's organization. These advancements are projected to significantly contribute to the organizations' success in the future, covering the "innovative products and processes" part. Moreover, about $60 \%$ of all project partners are already working on a joint follow-up project. According to Perkmann et al. (2011), this can be seen as a strong indicator of the long-term development of human and institutional capacities, covering the "advance the technology" part.

Using the R\&D Lifecycle Model (Perkmann et al., 2011) as a conceptual evaluation framework allows us to pinpoint which factors did, and did not, significantly influence a project's success - at least in the context of the technology transfer approach of the leadingedge cluster it's $O W L$. In the following, we will discuss in detail the findings regarding the different factors in the stages of the model.

\subsubsection{The R\&D lifecycle model's input stage: motivation, capabilities, and R\&D expenditure}

Starting with the "input" stage, results from the structural model (Fig. 1), the bivariate intercorrelations (Table 3), as well as the performance-importance-map (Fig. 2) all show littleto-no influence of motivation or capabilities, neither on the constructs in the subsequent "in process" stage, nor on the more distal factors in the "output" or "impact" stages, although the available literature has assumed these relationships (see e.g., Albats et al., 2018; Fernandes et al., 2017; Perkmann et al., 2011). However, these non-significant relations do not imply that the recipient's absorptive capabilities are irrelevant for successful technology transfer in general. We instead argue that the it's $O W L$ transfer approach was indeed successful in tailoring the project goals directly to the SME's demands: Taking the current situation of the company into account and focusing the project activities on solutions with a 
direct market orientation seems to negate the need for previous experience with technology transfer or extensive capabilities on the recipients' side. Thus, we would interpret the diminishing role of capabilities as a further confirmation for the efficacy of the it's OWL transfer approach in overcoming barriers related to absorptive capabilities.

Likewise, an SME's lack of motivation (operationalized as the SME's engagement during the initiation phase) seems to be compensated for by it's $O W L$ 's internal bridging organization, which - even though the cooperation was not initiated by the SME-seems to match the right cooperation partners and appropriately support both parties during the planning phase and the project proposal to reach a joint strategy (as indicated by the high performance of joint strategy, see Fig. 2; Dumitrescu et al., 2016; Fechtelpeter et al., 2017; Fechtelpeter et al., 2018), thus overcoming barriers related to finding the right partner.

Interestingly, even though the it's $O W L$ transfer projects are aimed at SME's with limited capabilities and limited resources, $R \& D$ expenditure is still a significant antecedent for both trust (see Fig. 1) and the desired "outputs" (see Fig. 2). Thus, taking together the importance of $R \& D$ expenditure as well as the rather low performance of commitment (see next paragraph), the transfer approach presented here was not able to fully overcome barriers related to limited resources, although, we would argue, their influence is limited compared to depictions in the literature (Fernandes et al., 2017; Perkmann et al., 2011; Seppo and Lilles, 2012).

\subsubsection{The R\&D lifecycle model's in-process stage: joint strategy, trust, and commitment}

It seems that especially a longer duration of the transfer project as a whole is helpful to build trust (see weights in Fig. 1). This latter aspect is not that surprising, given that trust is built through experience in collaborations, and that new teams must go through several excruciating phases before they can deliver results, all of which takes time (Tuckman \& Jensen, 1977). This suggests that future technology transfer programs should find ways to increase the minimal project duration, without alienating potential industry partners who might in general prefer shorter projects (Buganza et al., 2014). Indeed, within the "in-process" stage, the most important drivers within the present transfer approach are commitment and-by a wide margin - trust. Whereas commitment focuses on the transfer recipient alone, trust encompasses the academic partner and, as Oliver et al. (2020, p. 774) put it: "is an important part of the process because the interaction between the actors is based on it". The dominance of trust again underlines the strength that lies in the connections between the individual stakeholders, which exceeds the strength of a single stakeholder alone (Morlacchi \& Martin, 2009; also see e.g., van Wijk et al., 2008 arguing that trust is one of the most important drivers for knowledge transfer). Even though (as indicated in the performance measure in Fig. 2) inter-organizational trust within the transfer projects is already quite high, its strong influence on the desired outputs implicates that future transfer approaches should find ways to further facilitate the building of trust between the project partners.

One possibility to increase trust is indeed increasing the partners' commitment. As discussed by Dirks (1999), this might be especially important for partners working together only temporarily, as is the case in the projects discussed here. Commitment on the other hand can be strengthened by bringing together partners with complementary competences. These complementary competences ensure that individual inputs are unique and identifiable. This 
results in a high interdependence between partners and makes it obvious that goals can only be achieved if each side commits to the endeavor (Dirks, 1999). Moreover, complementary competences as well as prolonged cooperation should reduce motivational losses like social loafing, thus also boosting the individual effort (Harkins \& Perry, 1982; Hilkenmeier, 2018; Williams et al., 1989). Besides, commitment can be increased by bringing own effort into the project, again showing interest and ensuring a high level of participation (Barbolla \& Corredera, 2009; Liu \& Hsiao, 2019).

As can best be seen in Fig. 2 and contrary to expectations (based on e.g. Morandi, 2013), joint strategy did neither substantially influence constructs from the immediately subsequent "output" stage, nor from the "impact" stage. Again, we would argue that these nonsignificant relations do not imply that a common perception of the aspired goals and the way to reach them is irrelevant for successful technology transfer in general. Instead, the "performance"-aspect of Fig. 2 shows that the participating transfer recipients already perceived the joint strategy and the work of the it's $O W L$ bridging agency as quite successful, indicating a ceiling effect.

\subsubsection{The R\&D lifecycle model's output and impact stages: goals achieved, S\&T human capital, market impact, and new R\&D projects}

Turning to the interplay between the "output" and the "impact" stage, our results corroborate Bozeman et al.'s (2015, p. 7) statement that "one of the most critical objectives in almost all aspects of science and technology policy is building human and institutional capabilities, even aside from particular accomplishments reflected in discrete knowledge and technology outputs". Whereas these "discrete knowledge and technology outputs", i.e., the specific goals of the project at hand, could indeed explain the company's prospective market impact, they did not significantly impact the pursuit of new $R \& D$ projects (Fig. 1). Conversely, the acquisition of scientific and technical human capital additionally explains the commitment to new R\&D projects and thus influences the long-term ability of SMEs to conduct more R\&D on their own or in collaboration with partners. (Bozeman 2000; Cyert \& Goodman, 1997). However, as seen in the lower part of Fig. 2, S\&T human capital's actual performance is relatively low, indicating that future transfer approaches should put an even greater emphasis on enhancing the industry partners' capabilities.

A viable strategy, for instance, might be to support the partners during the planning phase to develop a promising realization strategy for the project. Transfer agents may reveal and communicate any planning inconsistencies that could prevent integration of the transferred knowledge within the organization. Furthermore, the planning should include activities for competence development in the project, which accompany the actual development tasks (e.g. qualification, joint processing of tasks for competence transfer). This should also be done in consideration of the fact that, although this may mean additional effort for the companies during the project, it clearly has a positive impact on follow-up integration activities.

\subsection{Implications for technology transfer approaches based on it's OWL}

Our findings show that the temporary secondment of scientists to jointly work on a practical project objective - which is directly tailored to the demands of the company-is an effective instrument to increase SMEs' participation in R\&D projects and technology trans- 
fer activities. It strengthens the links between individual stakeholders in the cluster (i.e., SMEs, RTOs, transfer agents, etc.), which, according to Morlacchi and Martin (2009), is more important for competitiveness and economic growth than the strength of any stakeholder alone. The it's OWL approach and the associated study thus help to concretize the development of transfer activities in cluster initiatives and to improve the oftentimes low participation of SMEs in transfer activities. Innovative activities of SMEs - both alone and with academic partners - have decreased in recent years (Badillo et al., 2017; Zimmermann, 2018); future transfer approaches might consider our findings to counteract this trend.

Furthermore, our results suggest that the it's $O W L$ transfer approach was indeed quite successful in overcoming barriers related to finding the right partner and limited absorptive capabilities. However, barriers related to limited resources seem to be reduced, but not lifted. Therefore, most promising starting points to further improve the transfer approach presented here are to (a) increase the projects duration without disregarding the requirement of companies that often want to set up more short-term projects (since project duration was the strongest driver within $R \& D$ expenditure), and (b) increase the companies' commitment, both of which should in turn facilitate inter-organizational trust and thus lead to the desired outcomes. The latter is particularly meaningful because our results confirmed the prominent role of trust in the literature for the success of transfer projects.

Future transfer approaches can build on these recommendations. In fact, it's $O W L$ is already working on implementing optimizations. After the initial funding period for the it's $O W L$ transfer projects ended in 2018, the cluster initiative refined the transfer approach for the second period of funding (2018-2025) based on the evaluation results. This encompasses two main changes.

The first and major change enables the overall transfer project to be split into two consecutive smaller projects. Whereas the first project focuses on analyzing the company's existing products, processes, business models, or services and conceptualizes possible advancements, the consecutive second project focuses on a concrete implementation. This split has several benefits: It allows to increase the overall project duration (to up to 18 month), while at the same time reducing the duration and thus expense in the first project (only up to 6 month) as cautioned by e.g., Buganza et al. (2014) or de Wit-de Vries et al. (2019). This allows for dynamic flows and chains of projects, rather than having one rigid, monolithic project structure that could be disincentive to partners due to overall length, or that would be too much of a risk in its entirety.

The secondment of scientists to the partner SMEs is intended in both project phases. As stated by Wit-de Vries et al. (2019, p.1252), this close "collaboration experience with a specific partner and learning how to deal with differences seems the best way to overcome differences in logic and goals". Thus, developing common goals, selecting a fitting technology and defining a promising implementation strategy is now a main component of the funded first project phase (in contrast, in the original transfer concept, these activities part of the non-fundable project proposal phase). As an additional result, the transferor (the RTO) is now much more obliged to co-develop a solution suitable for the SME: For one, because the transferor is funded to do so, and second, because funding of the second, larger project in contingent on the quality of the solution developed in the first project. Of course, learning about the capabilities of the respective partner and drawing up implementation plans during the first project helps building trust (Wit-de Vries et al., 2019). Moreover, it reduces misunderstandings, different expectations, and task uncertainty between the partners in the 
subsequent second project (Cummings \& Teng, 2003, Morandi, 2013). As an additional benefit, splitting the overall project into two smaller consecutive projects allows for an uncomplicated cancellation option. If one or both of the partners is unsatisfied with the collaboration itself or its results, they simply do not apply for the second project, minimizing any potential losses in resources. Moreover, since the proposal for the second project has to be reviewed as well, the it's $O W L$ 's management organization also has the chance to suggest comprehensive adjustments or even cancel the second transfer project, if the project plan has weaknesses, is inadequately developed or, in the opinion of the experts, is not technologically appropriate. Overall, this strengthens the role of the administrative organization.

The second change from the original transfer approach to the refined transfer approach is that transfer recipients now have to pay $20 \%$ (for SMEs up to 50 employees) or $40 \%$ (for SEMs up to 250 employees) of the RTOs' expenses. All other expenses are funded. Because the company wants to achieve an efficient use of its own resources, this change should in general lead to a higher project prioritization and thus increase commitment (Barbolla \& Corredera, 2009; Cummings \& Teng, 2003). This refers to both the company and the RTO, which will be demanded more strongly and intensively by the company.

All in all, between 2018 and the first half of 2021, additional 85 transfer projects with a total public funding of 2 million $€$ completed this refined transfer approach within the it's $O W L$ cluster. Based on the changes described above, we would predict that, compared to the original transfer projects evaluated here, these refined transfer projects should report higher levels of commitment and trust, and, as an effect, higher levels of S\&T human capital. Moreover, we would hypothesize that in the refined projects, the specific goals are achieved even more frequently than in the original projects, and that $R \& D$ expenditure, analogous to motivation and capabilities in the present study, does not influence the subsequent stages of the R\&D Lifecycle Model, thus further overcoming the barriers related to limited resources. Of course, further empirical studies are needed to test these hypotheses.

We expect our findings to be transferable to similar transfer approaches to industry-academia collaboration -though further research is needed on this. In summary, we recommend that future transfer initiatives include a secondment of scientists to the companies or at least a close partnership and a sufficiently long project duration to allow time for trust-building processes. In addition, we consider a continuous evaluation of the collaborations according to defined cycles to be essential to make optimizations, as in the case of it's $O W L$. We think that the instrument of the it's OWL transfer projects with its characteristics is very well suited to concretize the transfer activities in clusters and, in particular, to integrate SMEs more strongly into the cluster activities. It might also be an interesting framework for knowledge-based regional development in regions with weak knowledge structure and a low degree of attractiveness for non-local knowledge actors via satellite institutes (Conlé et al., 2021).

\section{Conclusions}

Our study shows that both input factors such as R\&D expenditure and psychological in-process factors such as trust and commitment play an important role in achieving project goals, building human capital, and market impact and initiating new R\&D projects in the long run. However, as mentioned, we have to interpret the findings in the context of the study, i.e., the 
technology transfer framework and the underlying it's $O W L$ cluster structure. Although we think that the findings can be beneficial for a broader range of technology transfer activities and cluster initiatives, we argue that the underlying holistic technology transfer approach as a whole was a major factor in generating the positive results reported by the transfer recipients. Within the it's $O W L$ innovation ecosystem, high-risk, long-term R\&D projects are implemented by large companies and RTOs that promise to generate outstanding competitive advantages and technological breakthroughs. By complementing these high-risk projects with low-to-moderate risk transfer projects to disseminate the results of the former one quickly and efficiently into application, it's $O W L$ offers companies of all sizes and scientific capacities technological solutions as a basis for innovation. Especially the long and close secondment of scientists into SMEs, which are most in need of and benefit the most from collaborative technology transfer programs, helps to lift or at least reduce barriers related to finding the right partner, limited absorptive capacity, and limited resources. Companies involved in the transfer projects presented here not only enhanced their S\&T human capital, but also engaged in further innovative research activities.

\subsection{Limitations and future research directions}

Future studies could attempt to replicate our findings by examining other transfer approaches to achieve generalization outside of it's $O W L$. In doing so, research should also overcome some of the limitations of the present study. For one, as explained in the procedure and sample section, the evaluation was conducted approximately three months after the end of each transfer project. Therefore, reliable objective data for market impact, which would be preferable here, are not yet available. A longitudinal study such as the one conducted by Ahn et al. (2018) would go beyond the scope of this article but represents a potential continuation of our research activities.

Similarly, although we use a robust analysis technique for simultaneous consideration of relationships between variables (Kline, 2016), we cannot draw causal conclusions. Because of the cross-sectional design, we can say that the observed covariance patterns between variables are consistent with the theoretically assumed structural model, but there may be other structural models to which this applies (cf. Stone-Romero \& Rosopa, 2008). The use of at least three measurement points in a longitudinal design and the simultaneous exclusion or control of confounding variables could provide further empirical evidence of causality (Maxwell \& Cole, 2007). However, this research design is difficult to establish in fieldbased evaluation studies like this one. Spector (2019), however, argued for the justification of cross-sectional field studies, which can provide valuable research impulses on which future longitudinal studies can build.

Lastly, we modeled our structural equation model after the underlying assumptions of R\&D Lifecycle Model (or at least, how we understood it). Therefore, factors in a given stage only influence factors in the immediate subsequent stage (e.g., capabilities influence trust), but not factors in more distal stages (e.g., from capabilities to goals achieved). Moreover, factors within one stage do not influence each other (e.g., from commitment to trust), even though previous literature suggests such relationships. Thus, the present results offer plenty of other plausible models that were not investigated here. However, readers interested in such multivariate relationships can calculate them easily by using the R function psych::setCor with the intercorrelation matrix of Table 3 as input (Revelle, 2019). 
Future research could also validate the R\&D Lifecycle Model with alternative constructs. In our study, we made a reasoned selection of constructs that can be mapped to the model stages. However, a broader investigation on antecedents and outcomes of transfer collaborations would be desirable. In addition, little is known to date about the long-term consequences of industry-academia collaborations. Future studies could, for example, investigate how success criteria (e.g., R\&D funding, revenue share with innovative products and services) develop over several years after project completion. Longitudinal methodological designs would allow to capture time courses, such as latencies in impact or possible wavelike trajectories.

\subsection{Outlook}

Our study contributes to a better understanding of the complex processes within industryacademia collaboration projects in the context of SMEs as well as in the realization of transfer instruments within the framework of clusters and innovation ecosystems. By considering individual competencies and resources as well as knowledge facets on the input side and organizational success components on the output and impact side, we map these processes holistically. Furthermore, we empirically validated the R\&D Lifecycle Model (Perkmann et al., 2011) on the micro-level. By looking at the innovation cluster it's $O W L$ we zoomed into an applied technology transfer approach. Our evidence that innovation clusters such as it's $O W L$ can increase the competitiveness of firms via successful transfer activities argues for the expansion of this concept, which is effortful but fruitful in practice. Further research to apply our findings to other transfer approaches is needed. However, our study offers valuable insights and provides starting points for further optimizing technology transfer from academia to industry. The results thus provide impulses for political decision-makers as well as for other management organizations of cluster initiatives that want to involve SMEs more closely and strengthen technology transfer between research institutions and companies in innovation ecosystems.

Supplementary Information The online version contains supplementary material available at https://doi. org/10.1007/s10961-021-09913-x.

Funding Open Access funding enabled and organized by Projekt DEAL.

Open Access This article is licensed under a Creative Commons Attribution 4.0 International License, which permits use, sharing, adaptation, distribution and reproduction in any medium or format, as long as you give appropriate credit to the original author(s) and the source, provide a link to the Creative Commons licence, and indicate if changes were made. The images or other third party material in this article are included in the article's Creative Commons licence, unless indicated otherwise in a credit line to the material. If material is not included in the article's Creative Commons licence and your intended use is not permitted by statutory regulation or exceeds the permitted use, you will need to obtain permission directly from the copyright holder. To view a copy of this licence, visit http://creativecommons.org/licenses/by/4.0/.

\section{References}

Ahn, S., Yoon, J., \& Kim, Y. (2018). The innovation activities of small and medium-sized enterprises and their growth: Quantile regression analysis and structural equation modeling. Journal of Technology Transfer, 43, 216-342. https://doi.org/10.1007/s10961-017-9570-3 
Ajzen, I. (1991). The theory of planned behavior. Organizational Behavior and Human Decision Processes, 50, 179-211. https://doi.org/10.1080/08870446.2011.613995

Albats, E., Fiegenbaum, I., \& Cunningham, J. A. (2018). A micro level study of university industry collaborative lifecycle key performance indicators. Journal of Technology Transfer, 43, 389-431. https://doi. org/10.1007/s10961-017-9555-2

Amesse, F., \& Cohendet, P. (2001). Technology transfer revisited from the perspective of the knowledgebased economy. Research Policy, 30, 1459-1478. https://doi.org/10.1016/S0048-7333(01)00162-7

Argote, L., Ingram, P., Levine, J. M., \& Moreland, R. L. (2000). Knowledge transfer in organizations. Organizational Behavior and Human Decision Processes, 82, 1-8. https://doi.org/10.1006/obhd.2000.2883

Audretsch, D. B., Lehmann, E. E., \& Wright, M. (2014). Technology transfer in a global economy. Journal of Technology Transfer, 39, 301-312. https://doi.org/10.1007/s10961-012-9283-6

Baba, Y., Shichijo, N., \& Sedita, S. R. (2009). How do collaborations with universities affect firms' innovative performance? The role of "Pasteur scientists" in the advanced materials field. Research Policy, 38(5), 756-764. https://doi.org/10.1016/j.respol.2009.01.006

Badillo, E. R., Galera, F. L., \& Serrano, R. M. (2017). Cooperation in R\&D, firm size and type of partnership: Evidence for the Spanish automotive industry. European Journal of Management and Business Economics, 26, 123-143. https://doi.org/10.1108/EJMBE-07-2017-008

Banal-Estanol, A., Macho-Stadler, I., \& Perez-Castrillo, D. (2013). Research output from university-industry collaborative projects. Economic Development Quarterly, 27, 71-81. https://oi. org/10.1177/0891242412472535

Bandura, A. (1977). Self-Efficacy: Toward a unifying theory of behavioral change. Psycho-logical Review, 84, 191-215. https://doi.org/10.1037/0033-295X.84.2.191

Barbolla, A. M. B., \& Corredera, J. R. C. (2009). Critical factors for success in university-industry research projects. Technology Analysis \& Strategic Management, 21(5), 599-616. https://oi. org/10.1080/09537320902969133

Barnes, T., Pashby, I., \& Gibbons, A. (2002). Effective University-Industry Interaction: A Multicase Evaluation of Collaborative R\&D Projects. European Management Journal, 20(3), 272-285. https://oi. org/10.1016/S0263-2373(02)00044-0

Bellini, E., Piroli, G., \& Pennacchio, L. (2019). Collaborative know-how and trust in university-industry collaborations: Empirical evidence from ICT firms. Journal of Technology Transfer, 44(6), 1939-1963. https://doi.org/10.1007/s10961-018-9655-7

Bercovitz, J., \& Feldman, M. (2008). Academic entrepreneurs: Organizational change at the individual level. Organization Science, 19(1), 69-89

Bishop, K., D’Este, P., \& Neely, A. (2011). Gaining from interactions with universities: Multiple methods for nurturing absorptive capacity. Research Policy, 40(1), 30-40. https://doi.org/10.1016/j. respol.2010.09.009

Bozeman, B. (2000). Technology transfer and public policy: A review of research and theory. Research Policy, 29, 627-655. https://doi.org/10.1016/S0048-7333(99)00093-1

Bozeman, B., Dietz, J. S., \& Gaughan, M. (2001). Scientific and technical human capital: An alternative model for research evaluation. International Journal of Technology Management, 22, 716-740. https:// doi.org/10.1504/IJTM.2001.002988

Bozeman, B., Rimes, H., \& Youtie, J. (2015). The evolving state-of-the-art in technology transfer research: Revisiting the contingent effectiveness model. Research Policy, 44, 34-49. https://doi.org/10.1016/j. respol.2014.06.008

Buganza, T., Colombo, G., \& Landoni, P. (2014). Small and medium enterprises' collaborations with universities for new product development: An analysis of the different phases. Journal of Small Business and Enterprise Development, 21(1), 69-86. https://doi.org/10.1108/JSBED-10-2013-0160

Champely, S. (2018). Pwr: Basic functions for power analysis. (Version 1.2-2.) https://CRAN.R-project.org/ package $=$ pwr

Chin, W. W. (2010). How to write up and report PLS analyses. In Esposito, V. E., Chin, W. W., Henseler, J., \& Wang, H. (Eds.), Handbook of partial least squares. Concepts, methods and applications (pp. 655-690). Springer

Cohen, J. (1988). Statistical power analysis for the behavioral sciences (2nd ed.) Lawrence Erlbaum Associates

Conlé, M., Kroll, H., Storz, C., ten Brink, T., (Online, \& First (2021). University satellite institutes as exogenous facilitators of technology transfer ecosystem development. Journal of Technology Transfer. https://doi.org/10.1007/s10961-021-09909-7

Cunningham, J. A., \& O'Reilly, P. (2018). Macro, meso and micro perspectives of technology transfer. Journal of Technology Transfer, 43, 545-557. https://doi.org/10.1007/s10961-018-9658-4 
Cummings, J. L., \& Teng, B. S. (2003). Transferring R\&D knowledge: the key factors affecting knowledge transfer success. Journal of Engineering and Technology Management, 20(1-2), 39-68. https://doi. org/10.1016/S0923-4748(03)00004-3

Curley, M., \& Salmelin, B. (2018). Open Innovation 2.0-The New Mode of Digital Innovation for prosperity and sustain-ability. Springer International Publishing. https://doi.org/10.1007/978-3-319-62878-3

Cyert, R. M., \& Goodman, P. S. (1997). Creating effective University-industry alliances: An organizational learning perspective. Organizational Dynamics, 25(4), 45-57. https://doi.org/10.1016/ S0090-2616(97)90036-X

De Wit-de Vries, E., Dolfsma, W. A., van der Windt, H. J., \& Gerkema, M. P. (2019). Knowledge transfer in university-industry research partnerships: a review. Journal of Technology Transfer, 44(4), 1236-1255. https://doi.org/10.1007/s10961-018-9660-x

Decius, J., \& Schaper, N. (2017). The Competence Management Tool (CMT)-A new instrument to manage competences in small and medium-sized manufacturing enterprises. Procedia Manufacturing, 9 , 376-383. https://doi.org/10.1016/j.promfg.2017.04.041

Decius, J., Schaper, N., \& Seifert, A. (2019). Informal workplace learning: Development and validation of a measure. Human Resource Development Quarterly, 30(4), 495-535. https://doi.org/10.1002/ hrdq. 21368

Demain, A. L. (2001). The relationship between universities and industry: The American university perspective. Food Technology and Biotechnology, 39(3), 157-160

Diebold, P., Vetro, A., \& Fernandez, D. M. (2015). October 22-23). An exploratory study on technology transfer in software engineering. [Conference session]. Proc. 9th International Symposium on Empirical Software Engineering and Measurement, Beijing, China. https://doi.org/10.1109/ESEM.2015.7321189

Dirks, K. T. (1999). The effects of interpersonal trust on work group performance. Journal of Applied Psychology, 84, 445-455. https://doi.org/10.1037/0021-9010.84.3.445

Dumitrescu, R., Gausemeier, J., Fechtelpeter, C., Ebbesmeyer, P., Hobscheidt, D., \& Kuehn, A. (2016). On the road to industry 4.0: Technology transfer in the SME sector. it's OWL Clustermanagement GmbH. https://doi.org/10.13140/RG.2.2.29061.37602

Farrell, A. M. (2010). Insufficient discriminant validity: A comment on Bove, Pervan, Beatty, and Shiu (2009). Journal of Business Research, 63(3), 324-327. https://doi.org/10.1016/j.jbusres.2009.05.003

Fechtelpeter, C., Kuehn, A., Dumitrescu, R., \& Ebbesmeyer, P. (2017). Integrated technology transfer concept for fostering innovation in SMEs. [Conference session], Proc. 26th International Association for Management of Technology Conference (IAMOT), May 14-18, Vienna, Austria. http://bestevent. management/event/7/session/19/contribution/115

Fechtelpeter, C., Dumitrescu, R., \& Kuehn, A. (2018). Supporting the planning phase of SME-tailored technology transfer projects. [Conference session]. Proc. 27th International Association for Management of Technology Conference (IAMOT), Birmingham, UK. https://www2.aston.ac.uk/migrated-assets/applicationpdf/aston-business-school/388089-IAMOT2018 paper 56.pdf

Feller, I., Ailes, C. P., \& Roessner, J. D. (2002). Impacts of research universities on technological innovation in industry: Evidence from engineering research centers. Research Policy, 31(3), 457-474. https://doi. org/10.1016/S0048-7333(01)00119-6

Fernandes, G., Pinto, E. B., Araújo, M., Magalhães, P., \& Machado, R. J. (2017). A method for measuring the success of collaborative university-industry R\&D funded contracts. Procedia Computer Science, 121, 451-460. https://doi.org/10.1016/j.procs.2017.11.061

Fornell, C., \& Larcker, D. F. (1981). Evaluating structural equation models with unobservable variables and measurement error. Journal of Marketing Research, 18, 39-50. https://doi. org/10.1177/002224378101800104

Garengo, P. (2019). How bridging organisations manage technology transfer in SMEs: An empirical investigation. Technology Analysis \& Strategic Management, 31(4), 477-491. https://doi.org/10.1080/0953 7325.2018.1520976

German Federal Ministry for Economic Affairs and Energy (2020). SMEs Digital-Strategies for the digital transformation. Berlin, Germany. https:/www.bmwi.de/Redaktion/EN/Publikationen/Mittelstand/ smes-digital-strategies-for-digital-transformation.pdf?_ blob=publicationFile \&v=5

Götz, M., \& Jankowska, B. (2017). Clusters and Industry 4.0-do they fit together? European Planning Studies, 25(9), 1633-1653. https://doi.org/10.1080/09654313.2017.1327037

Goller, M., \& Hilkenmeier, F. (forthcoming). PLS-based structural equation modelling: An alternative approach to estimate complex relationships between unobserved constructs illustrated with a replication study on the differential influence of predictors on professional learning activities. In M. Goller, E. Kyndt, S. Paloniemi, \& C. Damsa (Eds.). Methods for Researching Professional Learning and Development: Challenges, Applications and Empirical Illustrations, Springer

Günsel, A. (2015). Research on effectiveness of technology transfer from a knowledge based perspective. Procedia-Social and Behavioral Sciences, 207, 777-785. https://doi.org/10.1016/j.sbspro.2015.10.165 
Green, F. (2007). Demanding work. The paradox of job quality in the affluent economy. Princeton University Press

Grimaldi, R., \& von Tunzelmann, N. (2002). Assessing collaborative, pre-competitive R\&D projects: The case of the UK LINK scheme. R\&D Management, 32(2), 165-173. https://doi.org/10.1111/1467-9310.00248

Grimpe, C., \& Hussinger, K. (2013). Formal and informal knowledge and technology transfer from academia to industry: Complementarity effects and innovation performance. Industry and Innovation, 20, 683-700

Hair, J. F., Black, W. C., Babin, B. J., \& Anderson, R. E. (2014). Multivariate data analysis (7th ed.). Pearson

Hair, J. F., Hult, G. T. M., Ringle, C. M., \& Sarstedt, M. (2014). A primer on partial least squares structural equation modeling (PLS-SEM). Sage

Handoko, F., Smith, A., \& Burvill, C. (2014). The role of government, universities, and businesses in advancing technology for SMEs' innovativeness. Journal of Chinese Economic and Business Studies, 12, 171-180. https://doi.org/10.1080/14765284.2014.900968

Harkins, S. G., \& Perry, R. E. (1982). Effects of task difficulty and task uniqueness on social loafing. Journal of Personality and Social Psychology, 43, 1214-1229. https://doi.org/10.1037/0022-3514.43.6.1214

Harman, H. H. (1960). Modern factor analysis. Chicago, IL: University of Chicago Press

Hayter, C. S., Rasmussen, E., \& Rooksby, J. H. (2020). Beyond formal university technology transfer: innovative pathways for knowledge exchange. The Journal of Technology Transfer, 45, 1-8. https://doi. org/10.1007/s10961-018-9677-1

Henseler, J., Ringle, C. M., \& Sarstedt, M. (2015). A New Criterion for Assessing Discriminant Validity in Variance-based Structural Equation Modeling. Journal of the Academy of Marketing Science, 43(1), 115-135. https://doi.org/10.1007/s11747-014-0403-8

Herliana, S. (2015). Regional innovation cluster for small and medium enterprises (SME): A triple helix concept. Procedia-Social and Behavioral Sciences, 169, 151-160. https://doi.org/10.1016/j. sbspro.2015.01.297

Hicks, D. (1993). University-industry research links in Japan. Policy Sciences, 26, 361-395. https://doi. org/10.1007/BF00999478

Hilkenmeier, F. (2018). The impact of motive disposition on group performance. Cogent Psychology, 5, 1507123. https://doi.org/10.1080/23311908.2018.1507123

Hilkenmeier, F., Bohndick, C., Bohndick, T., \& Hilkenmeier, J. (2020). Assessing distinctiveness in multidimensional instruments without access to raw data-a manifest Fornell-Larcker criterion. Frontiers in Psychology, 11, 1-9. https://doi.org/10.3389/fpsyg.2020.00223

Hilkenmeier, F., Goller, M., Schaper, N., \& Online First. (2021). The differential influence of learner factors and learning context on different professional learning activities. Voca-tions and Learning. https://oi. org/10.1007/s12186-021-09266-4

Ibanez, M. J., Guerrero, M., Yanez-Valdes, C., Borros-Celume, S., \& Online First. (2021). Digital social entrepreneurship: the N-Helix response to stakeholders' COVID-19 needs. Journal of Technology Transfer. https://doi.org/10.1007/s10961-021-09855-4

it's OWL Clustermanagement GmbH (2020). About us. Paderborn, Germany. https://www.its-owl.com/ about-us/

Jones, O., \& Tilley, F. (Eds.). (2003). Competitive Advantage in SMEs: Organizing for Innovation and Change. Chichester: Wiley

Kauppila, O., Mursula, A., Harkonen, J., \& Kujala, J. (2015). Evaluating university-industry collaboration: the European Foundation of Quality Management excellence model-based evaluation of universityindustry collaboration. Tertiary Education and Management, 21, 229-244. https://doi.org/10.1080/13 583883.2015.1045550

Ketels, C. (2017). Cluster Mapping as a Tool for Development. Institute for Strategy and Competitiveness Harvard Business School, Boston, USA. https://www.hbs.edu/faculty/Publication\%20Files/Cluster\%20 Mapping\%20as\%20a\%20Tool\%20for\%20Development\%20_\%20report_ISC\%20WP\%20version\%20 10-10-17_c46d2cf1-41ed-43c0-bfd8-932957a4ceda.pdf

Ketels, C. H. M., \& Memedovic, O. (2008). From clusters to cluster-based economic development. International Journal of Technological Learning Innovation and Development, 1(3), 375-392. https://doi. org/10.1504/IJTLID.2008.019979

Kind, S., \& Meier, G. (2012). Developing Successful Creative \& Cultural Clusters-Measuring their outcomes and impacts with new framework tools. Oct. 2012. https://doi.org/10.13140/RG.2.2.31228.23681

Kline, R. B. (2016). Principles and Practice of Structural Equation Modeling (4th ed.). Guilford

LeBreton, J., \& Senter, J. L. (2008). Answers to 20 questions about interrater reliability and interrater agreement. Organizational Research Methods, 11(4), 815-852. https://doi.org/10.1177/1094428106296642

Leischnig, A., \& Geigenmüller, A. (2020). Examining alliance management capabilities in university-industry collaboration. Journal of Technology Transfer, 45, 9-30. https://doi.org/10.1007/s10961-018-9671-7 
Link, A. N., \& Rees, J. (1990). Firm size, university based research, and the returns to R\&D. Small Business Economics, 2(1), 25-32. https://doi.org/10.1007/BF00389891

Link, A. N., Siegel, D. S., \& Bozeman, B. (2007). An empirical analysis of the propensity of academics to engage in informal university technology transfer. Industrial and Corporate Change, 16(4), 641-655. https://doi.org/10.1093/icc/dtm020

Liu, T. H., \& Hsiao, Y. C. (2019). Fitting cooperative mode in inter-organizational strategic alliance: a perspective from innovative and financial performances. Journal of Technology Transfer, 44(1), 73-96. https://doi.org/10.1007/s10961-017-9593-9

Locke, E. A., \& Latham, G. P. (1990). A Theory of Goal-Setting and Task Performance. Prentice Hall

Lockett, N., Kerr, R., \& Robinson, S. (2008). Multiple Perspective on the Challenges for Knowledge Transfer between Higher Education Institutions and Industry. International Small Business Journal, 26(6), 661-681. https://doi.org/10.1177/0266242608096088

Masiello, B., Izzo, F., \& Canoro, C. (2015). The structural, relational and cognitive configuration of innovation networks between SMEs and public research organisations. International Small Business Journal, 33(2), 169-193. https://doi.org/10.1177/0266242613485610

Maxwell, S. E., \& Cole, D. A. (2007). Bias in cross-sectional analyses of longitudinal mediation. Psychological Methods, 12(1), 23-44. https://doi.org/10.1037/1082-989X.12.1.23

Motohashi, K. (2005). University-industry collaborations in Japan: the role of new technology-based firms in transforming the National Innovation System. Research Policy, 34(5), 583-594

Mora-Valentin, E. M., Montoro-Sanchez, A., \& Guerras-Martin, L. A. (2004). Determining factors in the success of R\&D cooperative agreements between firms and research organizations. Research Policy, 33(1), 17-40. https://doi.org/10.1016/S0048-7333(03)00087-8

Morandi, V. (2013). The management of industry-university joint research projects: How do partners coordinate and control R\&D activities? Journal of Technology Transfer, 38(2), 69-92. https://doi.org/10.1007/ s10961-011-9228-5

Morlacchi, P., \& Martin, B. R. (2009). Emerging challenges for science, technology and innovation policy research: a reflexive overview. Research Policy, 38, 571-582. https://doi.org/10.1016/j. respol.2009.01.021

Muller, P., Julius, J., Herr, D., Koch, L., Peycheva, V., \& McKiernan, S. (2017). Annual report on european SMEs 2016/2017-Focus on self-employment. European Commission. https://ec.europa.eu/docsroom/ documents/26563/attachments/1/translations/en/renditions/native

Nepelski, D., Van Roy, V., \& Pesole, A. (2019). The organisational and geographic diversity and innovation potential of EU-funded research networks. Journal of Technology Transfer, 44(2), 359-380. https://doi. org/10.1007/s10961-018-9692-2

O'Brien, R. M. (2007). A caution regarding rules of thumb for variance inflation factors. Quality and Quantity, 41, 673-690. https://doi.org/10.1007/s11135-006-9018-6

Oliver, A. L., Montgomery, K., \& Barda, S. (2020). The multi-level process of trust and learning in university-industry innovation collaborations. Journal of Technology Transfer, 45, 758-779. https://doi. org/10.1007/s10961-019-09721-4

Ones, D. S., \& Viswesvaran, C. (1996). Bandwidth-fidelity dilemma in personality measurement for personnel selection. Journal of Organizational Behavior, 17, 609-626. https://doi.org/10.1002/ (SICI)1099-1379(199611)17:6<609::AID-JOB1828>3.0.CO;2-K

Petruzzeli, A. M., \& Murgia, G. (2020). University-Industry collaborations and international knowledge spillovers: A joint-patent investigation. Journal of Technology Transfer, 45, 958-983. https://doi. org/10.1007/s10961-019-09723-2

Perkins, G. (2018). How does self-direction within learning operate to affect idea generation in small-medium enterprise contexts? Human Resource Development Quarterly, 28, 1-22. https://doi.org/10.1002/ hrdq. 21326

Perkmann, M., Neely, A., \& Walsh, K. (2011). How should firms evaluate success in university-industry alliances? A performance measurement system. R\&D Management, 41, 202-216. https://oi. org/10.1111/j.1467-9310.2011.00637.x

Plewa, C., \& Quester, P. (2006). Satisfaction with university-industry relationships: the impact of commitment, trust and championship. International Journal of Technology Transfer and Commercialisation, 5 , 79-101. https://doi.org/10.1504/IJTTC.2006.008654

Podsakoff, P. M., MacKenzie, S. B., Lee, J., \& Podsakoff, N. P. (2003). Common method biases in behavioral research: A critical review of the literature and recommended remedies. Journal of Applied Psychology, 88, 879-903

Porter, M. E. (1998). Clusters and the new economics of competition. Harvard Business Review, 76(6), 77-90. https://doi.org/10.1201/b14647-11

Porter, M. E. (2003). Locations, clusters, and company strategy. In: In Clark, G. L., Feldman, M. P., \& Gertler, M. S. (Eds.), The Oxfort handbook of economic geography (pp. 253-274). Oxfort Universtity Press 
Proskuryakova, L., Meissner, D., \& Rudnik, P. (2017). The use of technology platforms as a policy tool to address research challenges and technology transfer. Journal of Technology Transfer, 42, 206-227. https://doi.org/10.1007/s10961-014-9373-8

Rauch, E., Matt, D. T., Brown, C. A., Tower, W., Vickery, A., \& Santiteerakul, S. (2018). Transfer of Industry 4.0 to Small and Medium Sized Enterprises. Transdisciplinary Engineering Methods for Social Innovation of Industry 4.0: Proceedings of the 25th ISPE Inc. International Conference on Transdisciplinary Engineering. IOS Press. https://doi.org/10.1109/ieem.2018.8607477

Rauter, R., Globocnik, D., Perl-Vorbach, E., \& Baumgartner, R. J. (2018). Open innovation and its effects on economic and sustainability innovation performance. Journal of Innovation \& Knowledge, 4, 226-233. https://doi.org/10.1016/j.jik.2018.03.004

Revelle, W. (2019). psych: procedures for psychological, psychometric, and personality research. Retrieved April 4, 2021 from https://CRAN.R-project.org/package=psych

Rossi, F., \& Rosli, A. (2015). Indicators of university-industry knowledge transfer performance and their implications for universities: Evidence from the United Kingdom. Studies in Higher Education, 40(10), 1970-1991

Salas, E., Diaz Granados, D., Klein, C., Shawn Burke, C., Stagl, K. C., Goodwin, G. F., \& Halpin, S. M. (2008). Does Team Training Improve Team Performance? A Meta-Analysis. Human Factors, 50, $903-$ 933. https://doi.org/10.1518/001872008X375009

Salmi, P., \& Torkkeli, M. (2009). Success factors of interorganisational knowledge transfer: a case of collaborative public-private R\&D project.International Journal of Business Innovation and Research, 3(2),109-125. https://doi.org/10.1504/IJBIR.2009.022750

Sanchez, G., Trinchera, L., \& Russolillo, G. (2015). Plspm: Tools for partial least squares path modeling (PLS-PM). (Version 0.4.7) [Computer software]. https:/CRAN.R-project.org/package=plspm

Santoro, M. D., \& Bierly, P. E. (2006). Facilitators of knowledge transfer in university-industry partnerships: A knowledge-based perspective. IEEE Transactions on Engineering Management, 53(4), 495-507

Santoro, M. D., \& Chakrabarti, A. K. (2002). Firm size and technology centrality in industry-university interactions. Research Policy, 31, 1163-1180

Schuh, G., Woelk, S., \& Portland International Center for Management of Engineering and Technology -PICMET-. (2017). Design Framework of an Ecosystem for Network-Based Innovation. 2017 Proceedings of PICMET '17: Technology Management for Interconnected World. : Portland International Conference on Management of Engineering and Technology, PICMET 2017. July 9-13, 2017, Portland, Oregon, USA. https://doi.org/10.23919/PICMET.2017.812526

Schultz, C., Gretsch, O., \& Kock, A. (2020). The influence of shared R\&D-project innovativeness perceptions on university-industry collaboration performance. The Journal of Technology Transfer, 46(4), 1144-1172. https://doi.org/10.1007/s10961-020-09818-1

Seppo, M., \& Lilles, A. (2012). Indicators measuring university-industry cooperation. Discussion on Estonian Policy, 20(1), 204-225.

Sherwood, A. L., \& Covin, J. G. (2008). Knowledge acquisition in university-industry alliances: An empirical investigation from a learning theory perspective. Journal of Product Innovation Management, 25(2), 162-179. https://doi.org/10.1111/j.1540-5885.2008.00292.x

Spanos, Y. E., Vonortas, N. S., \& Voudouris, I. (2015). Antecedents of innovation impacts in publicly funded collaborative R\&D projects. Technovation, 36-37, 53-64. https://doi.org/10.1016/j. technovation.2014.07.010

Sparrow, P., Shipton, H., Budhwar, P., \& Brown, A. (2016). Human resource management, innovation and performance. Springer

Spector, P. E. (2019). Do not cross me: optimizing the use of cross-sectional designs. Journal of Business and Psychology, 34(2), 125-137. https://doi.org/10.1007/s10869-018-09613-8

Spithoven, A., Vanhaverbeke, W., \& Roijakkers, N. (2012). Open Innovation practices in SMEs and large enterprises. Small Business Economics, 41(3), 537-562. https://doi.org/10.1007/s11187-012-9453-9

Stolze, A., \& Sailer, K. (2021). online first) Advancing HEIs' third-mission through dynamic capabilities: The role of leadership and agreement on vision and goals. Journal of Technology Transfer. https://doi. org/10.1007/s10961-021-09850-9

Stone-Romero, E. F., \& Rosopa, P. J. (2008). The relative validity of inferences about mediation as a function of research design characteristics. Organizational Research Methods, 11(2), 326-352https://doi.org/10 $.1177 \% 2 F 1094428107300342$

Strategic policy forum on digital entrepreneuership (2016). Big data and B2B digital platforms: the next frontier for Europe's industry and enterprises. https://ec.europa.eu/docsroom/documents/18503

Tödtling, F., \& Kaufmann, A. (2001). The Role of the Region for Innovation Activities of SMEs. European Urban and Regional Studies, 8(3), 203-215

Tuckman, B. W., \& Jensen, M. A. (1977). Stages of small-group development revisited. Group and Organization Studies, 2, 419-426. https://doi.org/10.1177/105960117700200404 
Van Wijk, R., Jansen, J. J. P., \& Lyles, M. A. (2008). Inter- and intra-organizational knowledge transfer: A meta-analytic review and assessment of its antecedents and consequences. Journal of Management Studies, 45(4), 830-853

Villani, E., Rasmussen, E., \& Grimaldi, R. (2017). How intermediary organizations facilitate universityindustry technology transfer: A proximity approach. Technological Forecasting and Social Change, 114, 86-102. https://doi.org/10.1016/j.techfore.2016.06.004

Van Lancker, J., Mondelaers, K., Wauters, E., \& Van Huylenbroeck, G. (2016). The Organizational Innovation System: A systemic framework for radical innovation at the organizational level. Technovation, 52, 40-50. https://doi.org/10.1016/j.technovation.2015.11.008

Weckowska, D. M. (2015). Learning in university technology transfer offices: transactions-focused and relations-focused approaches to commercialization of academic research. Technovation, 42, 62-74. https:// doi.org/10.1016/j.technovation.2014.11.003

Williams, K., Nida, S. A., Baca, L. D., \& Latane, B. (1989). Social loafing and swimming: Effects of identifiability on individual and relay performance of intercollegiate swimmers. Basic and Applied Social Psychology, 10, 73-81. https://doi.org/10.1207/s15324834basp1001_7

Wirsich, A., Kock, A., Strumann, C., \& Schultz, C. (2016). Effects of university-industry collaboration on technological newness of firms. Journal of Product Innovation Management, 33(6), 708-725. https:// doi.org/10.1111/jpim.12342

Zaichenko, S. (2018). The human resource dimension of science-based technology transfer: lessons from Russian RTOs and innovative enterprises. Journal of Technology Transfer, 43, 368-388. https://doi. org/10.1007/s10961-017-9567-y

Zimmermann, V. (2018). KfW SME innovation report 2017-Trend towards fewer innovators continues.KfW Group. https://www.kfw.de/PDF/Download-Center/Konzernthemen/Research/PDF-Dokumente-Innovationsbericht/KfW-Innovationsbericht-EN/ KfW-SME-Innovation-Report-2017_EN.pdf

Publisher's Note Springer Nature remains neutral with regard to jurisdictional claims in published maps and institutional affiliations.

\section{Authors and Affiliations}

\section{Frederic Hilkenmeier ${ }^{1}$. Christian Fechtelpeter ${ }^{2} \cdot$ Julian Decius $^{3,4}$}

Frederic Hilkenmeier

frederic.hilkenmeier@hs-fresenius.de

Christian Fechtelpeter

christian.fechtelpeter@iem.fraunhofer.de

Julian Decius

julian.decius@uni-bremen.de

1 Fresenius University of Applied Sciences, Alte Rabenstr. 1, 20148 Hamburg, Germany

2 Fraunhofer Institute for Mechatronic Systems Design IEM, Zukunftsmeile 1, 33102 Paderborn, Germany

3 Department of Work- and Organizational Psychology, Paderborn University, Warburger Str. 100, 33098 Paderborn, Germany

4 Faculty of Business Studies and Economics, University of Bremen, Enrique-Schmidt- Straße 1, 28359 Bremen, Germany 